\title{
Arqueología de los paisajes medievales granadinos: medio físico y territorio en la costa de Granada
}

Antonio Malpica Cuello

CONSIDERACIONES DE PARTIDA.

En una reciente publicación de un curso sobre Arqueología del Paisaje, que se celebró en la Università degli Studi di Siena, el prologuista de la obra pone de manifiesto algunos de los problemas principales existentes en este campo y que merece la pena destacar como primer hilo conductor del presente trabajo. Advierte lo siguiente: "Sul piano operativo, questo genere di indagini, con la applicazione sistematica del survey, ha determinato uno straordinario incremento di conoscenza... In ambito teorico non si può nascondere che la Site Catchment Analysis risente di una eccesiva ridigità nella concezione del territorio; il suo quadro di riferimento, utile per società molto semplici, si revela inadeguato appena ci si trovi di fronte a situazioni socio-economiche un po' più complesse"(D'AGOSTINO 1992: p.19). Y más adelante añade: "Il bacino di sussistenza di una comunità umana può strutturarsi secondo sistemi di complementarità difficilmente riconducibili a situazioni geografiche semplici e prevedibili"(D'AGOSTINO 1992: p. 19).

Después nos referiremos en concreto a estas cuestiones. Ahora cabe hacer una reflexión anterior. La llamada Arqueología del Paisaje, traducción del término inglés Landscape Archeology, ha intentado desde un primer momento analizar las relaciones entre el hombre y el medio físico que le rodea. Parte, pues, de un hecho básico, que las sociedades humanas dejan huellas de su pasado, o mejor dicho de las formas en que se organizaban, en la Naturaleza. El debate de arranque es el establecimiento del papel que le corresponde a cada elemento (Hombre en cuanto ser social/Naturaleza). La aproximación de ambos conceptos significa el comienzo de una nueva etapa en la ciencia. Parte de un hecho actualmente incuestionable, que la vida de las sociedades se inserta en un medio ambiente, que las condiciona, y que éste se modifica por aquéllas. Para llegar a esta situación, lógicamente debió de producirse un cambio importante, consistente en la formación de una nueva imagen de la Naturaleza, primero, y de la Historia humana, más tarde. El paso de la Historia Natural a la Historia de la Naturaleza, que se debe en buena medida a la obra de Lamarck (BARSANTI 1979: pp. 99 y ss.), es el centro y el inicio de un debate. Sin embargo, Darwin sentó las bases definitivas de este nuevo campo para la ciencia. La ruptura consistió en desprenderse del concepto teológico imperante, a partir de una maduración epistemológica que arranca del positivismo y del cientifismo.

La propia evolución de los estudios sobre la Historia es asimismo fundamental. De una fase dominada por el moralismo y la Teología, se pasa a otra en la que el concepto de cultura como fase superior de lo seres vivos racionales impregna todo el conocimiento. La adopción de lo material como elemento básico está ligada al progreso de las ciencias de la Naturaleza. El libro de L. Morgan: La sociedad primitiva, publicado en 1877, y, anteriormente, la aparición del primer volumen de El Capital, 
de Carlos Marx, de 1867, son jalones importantísimos. Marcan una cesura fundamental, desde el momento en que ponen de manifiesto que la vida de los hombres está condicionada por elementos materiales y que hay posibilidades de conocer científicamente a las sociedades humanas. Es más, la aproximación a pueblos que no se habían desarrollado en la misma línea que las sociedades europeas, es la base de un acercamiento nuevo, pues permite conocer, en opinión de los autores de aquellas fechas, sociedades "primitivas", que era tanto como decir muy dependientes del medio físico en el que se insertaban. La Historia humana se comprende, a la vez, como prolongación y ruptura de la Historia de la Naturaleza.

¿Cómo definir y explicar las relaciones entre Hombre y Naturaleza? Han existido respuestas simplistas, como el determinismo y el posibilismo geográfico, que tantas discusiones ha generado entre los geógrafos'. Hay que partir de una concepción nueva. Las relaciones entre el Hombre y la Naturaleza se desarrollan en el espacio. No es el medio natural sólo el "teatro" en el que tienen lugar las actividades naturales y las culturales, sino que también hay que señalar que estas últimas influyen de manera importante en aquél. De la confluencia de las fuerzas naturales y de las sociales surge el medio geográfico, cuya expresión es el paisaje (KULA 1973). Las acciones entre el medio ambiente y el hombre dan lugar, pues, a lo que denominamos paisaje. Pero esta interrelación se nos muestra con frecuencia borrosa y sólo de forma descriptiva. El paisaje es especialmente, aunque no de forma total, una realidad que se ve por los hombres. Contiene, pues, elementos psicológicos, que impregnan su conocimiento y su percepción, pero también realidades que se pueden categorizar. Como ha puesto de manifiesto uno de sus principales estudiosos españoles (GONZÁLEZ BERNÁLDEZ 198I), en él se puede distinguir entre fenosistema y criptosistema. Aquél es un conjunto de elementos perceptibles, mientras que éste es de una observación más difícil. Dicho de otra manera, el paisaje es una realidad física, pero también humana.
La relación Hombre/Naturaleza es dialéctica y se expresa principalmente en el paisaje. Partiendo de esa primera constatación, hay que establecer unas ciertas cuestiones de interés:

I.- No hay medios físicos favorables o desfavorables en sí mismos y de manera absoluta. Hay una variabilidad histórica claramente perceptible en el paisaje y que se puede expresar en lo que denominamos fenosistema. Es, así, el caso de los recursos naturales, que sólo tienen posibilidades en cuanto se conocen sus utilidades (KULA 1973: p. 528). Un ejemplo importante es el de la utilización del agua en al-Andalus como elemento de unas nuevas formas productivas, en las que la aparición de plantas hasta entonces desconocidas o apenas usadas tienen un papel importantísimo.

2.- Se puede decir que la Naturaleza tiene una mayor influencia sobre los grupos humanos cuando es menor el nivel existente. Este principio general debe ser, no obstante, matizado. Hay límites diferenciales de la apropiación de la Naturaleza por parte de los hombres. Son igualmente sociales. En la sociedad capitalista, la dominación de la Naturaleza, por el desarrollo de las fuerzas productivas, genera una dependencia creciente por los límites físicos de la Naturaleza.

De la confluencia de tales relaciones surge el concepto de espacio. No es sólo que tengan lugar en él como suceden en el tiempo, sino que la adopción de tal o cual espacio es una opción social. En consecuencia, la ordenación espacial es una acción que es ejercida por las sociedades, basada en factores ecológicos y sociales. Si se explica con mayor precisión se puede decir que aparecen tres subconjuntos:

I.- el medio natural con sus factores abióticos (la masa gaseosa y el líquido y el mineral, esencialmente) y bióticos (vegetación y fauna);

2.- las estructuras técnicas creadas por el hombre, $y$

3.- el medio social.

\footnotetext{
I Un planteamiento general sobre estas cuestiones, en HUMBERT, A.: "Sites et milieu naturel", en NOYÉ, G. (edit.): Structures de I'habitat et occupation du sol dans les pays méditerranéens: l'apport de l'Archéologie extensive. Roma-Madrid, 1988, pp. 297-300.
} 
Ahora bien, no pueden ser considerados elementos aislados o situados en una emulsión, sino que se integran en un conjunto interrelacionado. De ese modo, no hay que excluir ninguno de los subconjuntos señalados ni tampoco las interconexiones que hay entre ellos. Eso es lo habitual de determinadas corrientes que han tenido, en nuestra opinión con cierta lógica, una gran difusión, sin discusión científica. Podemos, pues, decir con Carandini: "Incluso reconociendo la gran importancia del 'materialismo cultural' para el objetivo de este estudio que estamos realizando, no podemos dejar de ponernos en guardia contra el materialismo abstracto y mecánico, el determinismo tecnológico-ambiental que está expresado por una ideología que parece tener fundamentalmente miedo de sacar a la luz los aspectos políticos y sociales de la producción (las relaciones del hombre con el hombre siempre han sido vistas por las clases dominantes y por sus intelectuales como bastante más peligrosas que las del hombre con la naturaleza)" (CARANDINI 1984: p. 76).

El análisis arqueológico es esencial para poder plantear cuestiones de este tipo. Pero no es suficiente con un yacimiento determinado ni siquiera un conjunto de los mismos, sino que es preciso un examen del espacio en que se insertan. Al mismo tiempo no es posible establecer unas pautas de los asentamientos sin tener en cuenta el medio físico y la acción humana. La técnica de la prospección arqueológica, que no significa sólo la identificación de yacimientos, es esencial para establecer las bases elementales de trabajo. Con estas sencillas palabras Graeme Barker lo pone de relieve: "Per mezzo delle ricognizioni, gli archeologici possono raccogliere informazioni circa i processi socio-economici e ambientali verificatisi durante milleni di insediamento scala regionale" (BARKER 1988: p. 137).

Hay suficientes elementos para evaluar las cuestiones que venimos enunciando. En primer lugar, hemos de señalar que el conoci- miento histórico que se deriva de la Arqueología tiene unas peculiaridades importantísimas con respecto a otras fuentes históricas. Este problema, que procede de una distinción quizás falsa, no se plantea en todas las etapas históricas que se pueden analizar. Es evidente que para un prehistoriador hay que hacer otros planteamientos y nunca se llega, por ejemplo, a una confrontación entre los testimonios escritos y los propiamente arqueológicos. No es menos cierto, sin embargo, que el papel de la Antropología ha sido relevante en los últimos tiempos para la Arqueología (BINFORD 1988). Incluso desde esta perspectiva, la confrontación entre las diversas materias que confluyen en el análisis de las sociedades es un hecho incuestionable a poco que se reflexione o incluso que se practique el propio trabajo arqueológico. En el fondo queda la necesidad de definir la propia Arqueología, para lo cual se ha optado tanto por caracterizarla como ciencia independiente, alejada de la Historia y de la Antropología, como inserta en una u otra materia². Sin entrar en una discusión más a fondo, $y$ aun siendo conscientes que la Nueva Arqueología está presente en este caso, hay que poner de relieve que la acción del medio físico sobre las sociedades humanas se ha tenido muy en cuenta. Los análisis espaciales en Arqueología no tardaron en surgir (HODDER y ORTON 1990). Los planteamientos que se pueden ver son esenciales para la organización del espacio y, lógicamente, para la relación del Hombre con la Naturaleza. El arranque parte de las sociedades menos complejas en donde el Site Catchment Analysis es esencial. Pero, como señalaba Bruno D'Agostino, según la cita hecha más arriba, es un modelo que se resiente de un exceso de rigidez y que no tiene apenas validez para sociedades más complejas que aquéllas a las que se ha aplicado en sus inicios. El mismo D'Agostino, recuérdese, aclara que las sociedades humanas no pueden quedar reducidas a situaciones geográficas simples y previsibles.

2 La bibliografía es abundantísima. Baste con señalar algunas obras de contenido más o menos específico: HODDER, I. : Interpretación en Arqueología. Corrientes actuales. Barcelona, 1988; KLEJN, L. S.: "To separate a centaur: on the relationship of arcehaeology and history in Soviet tradition". Antiquity (67), 255, pp. 339-348, y HENSEL, W.: "Archeologia. Contenuto e ambito", en DONATO, G. y otros: Teoria e pratica della ricerca archeologica. I. Premesse metodologiche. Turín, 1986, pp. 19-31. 
Para expresar la relación del hombre con el medio natural, sobre todo en sociedades más evolucionadas, hay que acudir a elementos diversos y todos ellos examinarlos a partir de una nueva estrategia científica. En el caso de la Arqueología medieval el debate sigue estando, aunque nos pese y consideremos que se haya falseado un tanto, en la diversidad de datos y en la diferente forma de obtenerlos. La relación, cuando menos problemática, de las fuentes escritas con las arqueológicas ciertamente ha viciado las perspectivas de un avance en la investigación. No es raro todavía hallar investigadores de una u otra procedencia que buscan un dato preciso del que carecen en su respectivo campo en el otro. El grado de subsidiaridad es la nota dominante. Pero hay otra cuestión añadida. La Arqueología medieval ha sido considerada espúrea por unos y otros, es decir por los arqueólogos en el sentido puro y duro del término, y por los medievalistas, siempre atentos a la documentación escrita.

Sin duda, nadie duda de que sea preciso entender los procesos históricos a partir de esa nueva relación entre Hombre y Naturaleza, a condición, claro está, que se extienda el concepto de la propia Arqueología y quede integrado en una visión a la vez antropológica e histórica. La oposición que se ha generado es fruto de una especialización necesaria, pero que carece del necesario debate teórico conjunto. En este sentido la Arqueología medieval, surgida en España en el seno de un debate historiográfico aun incipiente pero prometedor ${ }^{3}$, ha mostrado las posibilidades de conocimiento de una problemática histórica hasta ahora desconocida. A partir de una práctica ya más o menos consolidada y de algunas elaboraciones teóricas, se han ido sentando las bases mínimas para establecer unas líneas de investigación en el sentido expresado más arriba. Al tratarse de una sociedad más compleja que las prehistóricas y con una relación más diversa con la Naturaleza, las dificultades del trabajo son de diferente índole.

En el campo concreto de nuestra Arqueología medieval la investigación se ha centrado especialmente en el mundo andalusí. Esto añade una dificultad aún mayor, porque se trata de una sociedad que no ha surgido de la transformación de la anterior y que no va a dejar huellas, al menos en España, porque desapareció de la Península Ibérica. Como es natural, en el proceso de su formación y, sobre todo, de su destrucción las fuentes escritas han sido abundantes y permiten conocerla en unos momentos precisos, aunque conflictivos. Si unimos esta situación al hecho ya mencionado de la importación de modelos de otras experiencias científicas, el resultado es la producción de una práctica arqueológica compleja para analizar con detenimiento y un debate lastrado de vicios iniciales.

Antes de entrar de lleno en esta problemática, habrá que señalar que el análisis arqueológico se ha basado en la denominada Arqueología extensiva, que puede parangonarse con la llamada del paisaje. Jean-Marie Pesez, en el estudio introductorio de la parte dedicada a la investigación sobre los habitats, publicado en Castrum 2 (PESEZ 1988), ha puesto de manifiesto las líneas de partida. Así, señala: "L'archéologie extensive était (...) présentée comme la solution idéale à l'un des problèmes que pose la recherche archéologique: son caractère ponctuel, partiel, discontinu"(PESEZ 1988: p. 129).

Pero ha sido Graeme Barker quien ha planteado algunas de las cuestiones fundamentales de la llamada Arqueología del paisaje (BARKER 1986). En primer lugar, nos habla de la inexistencia de una definición de este tipo de Arqueología ${ }^{4}$, para más adelante señalar que son numerosas las técnicas precisas para su

\footnotetext{
3 Hemos hecho un primer balance, siempre provisional, en nuestro trabajo: "Historia y Arqueología medievales: un debate que continúa", en MONTANARI, M. y otros: Problemas actuales de la Historia. Terceras Jomadas de Estudios Históricos. Salamanca, 1993, pp. 29-47.

4 "Non c'è una definizione accettata di archeologia del paesaggio, ma penso che per la maggioranza degli archeologi il termine abbia assunto il significato di studio archeologico del rapporto tra le persone e l'ambiente nell' antichità, e dei rapporti tra la gente e la gente nel contesto dell'ambiente in cui abitava" (BARKER 1986 p. 7. )
} 
conocimiento5. Pero sobre todo destaca: "Le due fondamentali esigenze dell'archeologia del paesaggio sono probabilmente la prospettiva diacronica, o che copre periodi diversi, e l'approccio eclettico e plurisdisciplinare..."(BARKER 1986: p. 8).

Definida esencialmente por la práctica, cuya técnica esencial es la prospección arqueológica, esta Arqueología necesita dotarse al mismo tiempo de una teoría que necesariamente ha de vertebrar todas las ciencias que en ella intervienen. La aproximación a la Geografía, partiendo del análisis de los paisajes y de los territorios, el recurso a la Antropología, buscando las raíces culturales y sus pervivencias, el examen de las fuentes escritas, todo ello debe estar al servicio de una estrategia científica que, en nuestra opinión, tras todo lo dicho, es clara: la relación entre la sociedad concreta que se examina y el medio en el que se inserta y al que transforma. Así, la técnica de aproximación y la metodología de trabajo ha de distinguir la teoría general de los puntos de partida.

En este sentido, el propio Barker ha señalado: "molte ricognizioni classiche sono state esplicitamente ideate allo scopo di splorare il territorio, conosciuto o presunto, di un'antica città. Questo approccio può offrire il vantaggio di un preciso modello territoriale costruito attraverso le fonti documentarie, ma la ricognizione archeologica devi poi produrre dati su scala spaziale che possano mettere alla prova questo modello e che possano essere ad esso paragonati, invece di venire soltanto inseriti nel territorio previsto e confermare (ma in modo ingannevole) le supposizioni esistenti circa la sua natura" (BARKER 1988: p. 138).

Aunque el planteamiento general es el habitual, no quiere decir que las soluciones empleadas halladas fuesen siempre las más correctas. A partir de su experiencia personal sobre la sociedad andalusí, Pierre Guichard puso de manifiesto el camino a seguir en la investigación sobre esta temática tan claramente arqueológica de la relación entre Hombre/ Naturaleza: "Il n'est pas question non plus de réserver à l'historien le monopole de la synthèse des données rassemblées par d'autres spécialistes. Mais je ne crois pas non plus qu'il soit possible à chaque chercheur d'être en même temps et avec une égale compétence philologe, archéologue et historien" (GUICHARD 1986: p. 189).

El problema estriba en que un análisis de tales características no se puede llevar a cabo sin el concurso de numerosas técnicas, pero menos sin un proyecto científico. Esto ha querido decir casi siempre la búsqueda de un modelo y su contrastación. Mientras que para los prehistoriadores, por ejemplo, el modelo se basa en el análisis antropológico y etnológico, para los medievalistas el peso de las fuentes escritas ha sido fundamental. Eso quiere decir que hay que discutir, desde una dinámica diferente, cuál es el papel de cada tipo de datos obtenidos en la investigación.

Las fuentes escritas han generado hasta fechas muy recientes el principal, por no decir único, debate historiográfico en la Historia Medieval. Y esto no se puede ocultar ni siquiera minusvalorar, sino apreciar en su verdadera dimensión. El análisis ha quedado, pues, condicionado y ha dado lugar al establecimiento de modelos ceñidos a ellas. El más significativo de todas es el creado por Pierre Guichard, punto de arranque de otros muchos trabajos y de una discusión, desgraciadamente restringida, que aún continúa. En su importante obra y a lo largo de imnumerables contribuciones Guichard ha ido trazando una panorámica muy densa ${ }^{6}$. Es imprescindible en el caso presente hacer un breve resumen. Para el autor, la sociedad andalusí es cualitativamente diferente de la occidental. Se expresa de muy diversas formas,

5 “'Lo studio del paesaggio archeologico abraccia oggi una gamma molto ampia di tecniche, alcune specificamente archeologiche, altre prese in prestito o adattate dalla geografia umana e fisica... Inoltre, lo studio di un paesaggio dell'antichità per essere completo deve anche comprendere normali scave e l'analisi di tutti i dati ottenuti, sia biologici sia dei manufatti e, per quanto riguarda i periodi storici, l'integrazione dell'archeologia con le ricerche documentarie". (BARKER 1986 p. 7. )

6 Un análisis de su obra en MALPICA CUELLO, A.: "Ensayo introductorio" al libro de GUICHARD, P.: Al-Andalus. Estructura antropológica de una sociedad islámica en Occidente. Granada, 1994 (reedición del original de Barcelona, 1976). 
entre ellas y muy claramente, a niveles materiales. La organización espacial y el poblamiento son fundamentales en ese sentido. El elemento más significativo de la sociedad feudal, el castillo, tiene, sin embargo, un sentido distinto en la andalusí. Distingue entre las estructuras defensivas que cubren pequeñas villas y los castillos más alejados y retirados de las zonas pobladas. En aquéllas existían tres elementos diferenciados: la villa amurallada, el albacar y el castillo propiamente dicho, mientras en éstos había sólo los dos últimos (albacar y castillo propiamente dicho). Advierte que la técnica constructiva empleada es el tapial (cajones de mortero de cal y piedras con un encofrado de madera), singular en este tipo de edificios, y que son estructuras arquitectónicas en cierto modo elementales (muros de un valor defensivo desigual, a veces reforzados por torres, pero que normalmente siguen el relieve y sólo cubren los puntos más débiles y sin protección natural). Estas fortalezas, situadas en un ámbito rural por lo común, se hallaban insertas en un vasto territorio. La relación entre las estructuras defensivas y los espacios rurales se hace en un pie de igualdad, de manera que éstos, en donde hay núcleos de diversa caracterización, no son controlados por aquéllas. No cabe duda que son el punto focal en el que se apoya el Estado, pero la corresponsabilidad defensiva, que se aprecia en el caso de la sofra (GUICHARD 1979), muestra que las estructuras rurales de poblamiento tienen un peso importante en la propiedad y, en consecuencia, en la toma de decisiones. Los núcleos campesinos son de dos tipos por lo general: rafales y alquerías. En el primer caso es una propiedad privada de un solo dueño, quizás vinculado al Estado; en el segundo, las alquerías son a modo de una comunidad rural, formada por una decena de casas, hogares o familias, que se dedicaban a la explotación de un espacio agrícola sin depender social ni económicamente de un dueño eminente del suelo. Esta realidad aparece gracias a la utilización de nombres gentilicios para designar a esos núcleos, lo que pone de manifiesto que se trata de grupos humanos fuertemente cohesionados por el parentesco de tipo clánico-tribal.
La organización espacial y, lógicamente, la distribución funcional, del castillo pone de relieve esas relaciones. El albacar es un espacio amurallado, pero en el que no vive nadie, sino que sirve de refugio a los hombres y ganados de las poblaciones del distrito; el donjon, término tomado de la castellología feudal francesa, es el lugar de residencia de tropas y alcaide.

El planteamiento de Guichard está claro: se puede dar una sociedad en la que los lazos tribales sean fuertes en la base $y$, al mismo tiempo, haya un Estado. Para él, el Estado es una cosa y las comunidades campesinas son otras.

El primer punto que llama la atención es la pervivencia de las estructuras tribales, enfrentadas al Estado desde los primeros tiempos de al-Andalus, que van a mantenerse, sobre todo en el mundo rural, gracias a la segmentación. Ciertamente, no puede tratarse de algo inmanente de la propia sociedad, sino que debe basarse en una realidad material. Es Miquel Barceló quien ha puesto de manifiesto algunos de los aspectos esenciales del tema. Así, señala con claridad: "Por ello, las comunidades campesinas irrespectivamente de su origen o formación cronológica, han de tender a adoptar los comportamientos sociales tribales. Es decir, el medio tribal produce tribus. La tribalidad, en este sentido preciso, no es sólo una importación étnica del medio árabe o bereber, sino una forma de organizar los procesos de trabajo de las comunidades campesinas y definir las relaciones sociales con las otras comunidades" (BARCELÓ 1988, pp. 107- | 08).

El problema estriba, pues, en el hecho de que la organización espacial no tiene sentido sin un análisis de los procesos de trabajo. Su investigación la ha conducido siempre en esa línea. Por eso, aparte de los trabajos sobre toponimia, que en gran medida se han centrado en el caso de Mallorca', su aportación en los últimos tiempos ha girado en torno a la que él mismo ha denominado Arqueología hidráulica. Sobre ella ha elaborado unos prin-

\footnotetext{
7 Una buena parte de ellos han sido recopilados en un libro: BARCELÓ, M. (1984):: Sobre Mayūrqa. Palma de Mallorca, espec. I07-I08.
} 
cipios teóricos de interés, a los que también han contribuido algunos de sus discípulos (BARCELÓ y otros 1995). Su principal línea argumental es que los espacios irrigados mantienen y cohesionan a los grupos campesinos. El diseño de los mismos lleva implícitos unos códigos no sólo técnicos sino sociales. Los perímetros irrigados se calculan en función de los núcleos habitados que se crean, de manera que un aumento de población obliga a una segmentación. La reproducción de este tipo de sociedad está, pues, asegurada. La actividad estatal quedaría reducida a la ciudad y su alfoz, en donde las áreas de cultivo irrigadas estaban orientadas hacia el mercado urbano y para satisfacer a las necesidades de las clases urbanas.

El regadío es, pues, esencial para comprender al-Andalus. Si lo es a niveles políticos, sociales y económicos, no es menos cierto que se manifiesta en la organización espacial de los territorios campesinos. A este respecto dice Barceló: "La pauta de los asentamientos es siempre fundamentalmente la misma. El espacio hidráulico creado mediante la construcción de terrazas, que modifican las pendientes naturales y que son, por decirlo así, la energía que asegura el transporte del agua, determina la instalación de la zona de residencia, la alquería, que siempre está situada justo por encima de la línea de rigidez, o sea por encima de la acequia principal de distribución"(BARCELÓ 1989: p. XXX).

Así pues, en rigor, la denominada Arqueología hidráulica se integra en la Arqueología del paisaje. No se limita sólo al espacio cultivado, sin tener en cuenta otros componentes del conjunto, pues entonces sería en una simple morfología, en el mejor de los casos. Probar que los sistemas hidráulicos son coherentes con una determinada sociedad y con un poblamiento es posible y deseable. Recuérdense en tal sentido lo que pone de relieve Miquel Barceló: "La estructura social así producida contiene todos los elementos necesarios para instaurar un orden hidráulico perdurable cuyo reglamento, pactado, se constituye en la sola autoridad legítima y suficiente, incluso en el caso de que el espacio ordenado sea el resultado de una decisión de un poder (sulțān o feudal) exterior a las comunidades campesinas. El orden social hidráulico es tan rígido como su propio espacio, como la propia unidad tecnológica que lo sustenta y, a su vez, lo perpetúa" (BARCELÓ 1989: p. XXXIII).

La adopción de este modelo lleva aparejada necesariamente el estudio de los asentamientos o zonas de residencia con los espacios de cultivo. De otro modo habría que confiar sólo en los datos de las fuentes escritas. Pero no siempre lo permiten y en todo caso no se puede identificar automáticamente una estructura constructiva por una referencia documental, salvo en contadas ocasiones. Sólo un análisis propio de la Arqueología del paisaje puede permitir una secuencia temporal adecuada, en vez de ofrecer una escala demasiado amplia. De todas formas, hay que advertir que la cronología de un espacio agrícola no puede ser equiparable a la de un documento, como parece evidente (BARCELÓ en prensa).

Ese sentido de intemporalidad, que surge la mayor parte de las veces de las referencias de las fuentes o de un estudio morfológico, trae inevitablemente consigo otro de inmutabilidad. Manuel Acién advirtió claramente el problema: "Esta teoría posee el enorme mérito de definir la formación social en que se integra la población rural, así como su forma de reproducción, asimilando a población inserta en otras formaciones sociales (iindígena?, iurbana?). Pero el problema radica en aceptar una cierta inmutabilidad, tan sólo desafiada por un Estado convertido en superestructura al margen que se impone sólo cuando tiene medios para ello" (ACIÉN 1989: p. 142).

Para intentar conocer los orígenes de esta formación social, Acién enriquece el modelo de partida e introduce elementos dinámicos. Se inspira en el análisis de las fuentes, aunque sugiere cómo examinar los restos arqueológicos a partir de él. Al mismo tiempo, plantea la cuestión desde la perspectiva que inició Pierre Guichard, la de los castillos. éstos son los elementos substanciales de las relaciones conflictivas entre las diferentes formaciones que se enfrentan en el proceso de gestación del 
Estado islámico de al-Andalus. Consciente de la dificultad del problema, Manuel Acién señala: "Lo restante del título "Poblamiento y fortificación" implica que se entienda como un problema histórico y no simplemente arqueológico, lo cual quizá pueda defraudar a alguien; sin embargo, pienso que es el tratamiento adecuado.

Y, como consecuencia de esto, utilizaré todas las fuentes disponibles, las arqueológicas tanto en su vertiente monumental como las derivadas de la llamada Arqueología extensiva, así como los instrumentos necesarios para su identificación, siendo lamentable a este respecto que a veces se presenten prospecciones realizadas con un gran rigor metodológico, pero que, sin embargo, concluyen con una definición cronológica de "islámico" o "medieval".

Las fuentes escritas, entendidas sin ningún tipo de preeminencia sobre las anteriores, se utilizarán en cuanto ayudan a la interpretación de los restos materiales, pero también al entendimiento de los procesos" (ACIÉN 1989: p. I40).

Es evidente que desde el nivel de los presupuestos generales la propuesta es irreprochable, pero no cabe duda que con frecuencia los datos procedentes de las fuentes escritas tienen un mayor peso específico en los trabajos concretos que los más puramente arqueológicos. La oposición entre ambos es sencillamente una tontería. Lo que importa es la formulación de una estrategia científica y su desarrollo. El debate historiográfico debe de proceder de unos y otros en pie de igualdad. Sin embargo, no es menos cierto que los datos llamados históricos están más perfilados que los arqueológicos. Se debe a una mayor tradición en aquel campo que en éste, pero también a la poca elaboración de ellos e incluso al tratamiento diferenciado que requiere cada uno. Contamos con un corpus de datos de cierta importancia, que procede en su práctica totalidad de las Crónicas de determinados períodos. Carecemos para la época árabe de documentos de archivo, o son casi inexistentes, ya que los que han llegado hasta nosotros son de los tiempos finales del reino nazarí, lógicamente muy alejados de las primeras épocas. Las fuentes escritas de esa tradi- ción cultural se refieren básicamente a los conflictos habidos entre el poder político estatal y determinados grupos sociales refractarios a caer bajo su dominio, como sucede especialmente con la etapa de establecimiento del Estado islámico. Es lógico, pues, que tengamos una imagen muy mediatizada por esas cuestiones. Los datos que aparecen tienen asimismo una gran precisión cronológica, pero los lugares que se mencionan lo son de manera discontinua, aunque haya unos que aparezcan con más regularidad que otros. Así, a guisa de ejemplo, podemos recoger el texto siguiente, que narra una campaña de 'Abd alRahmān III contra la cora de Elvira:

"Luego fue contra las fortalezas que tenía el perverso Umar b. Hafșūn en la cora de Elvira, tras acabar con las de Jaén, y no dejó allí quien se le opusiera, aunque aquellas fortalezas agregadas a los dominios de Umar b. Hafșūn se habían negado a rendirse al sultán, cuando la gente de la cora se había apresurado a hacerlo, entrando en sus filas. Las sitió una por una, pero se le resistió la de Juviles por su lejanía y la dificultad de alcanzarla con catapultas: como allí estaban algunos cristianos del perverso CUmar, valerosos y enérgicos, resistieron bien, pero anNāșir, empeñado en combatirlos, hizo construir una base, donde emplazó la catapulta, alcanzándoles con sus piedras, y les cortó el agua y apretó el cerco hasta vencerlos, siendo tomada la fortaleza al asalto y muertos cuantos partidarios del rebelde 'Umar allí había, lo que le hizo mella, cayendo con ésta todas las fortalezas de Ferreira y alrededores. El maldito $\hat{Y}_{a}$ 'far, hijo preferido y heredero de su perverso padre, que estaba en Salobreña, asustado con estos triunfos sucesivos, huyó de allí de noche, uniéndose con su padre en su capital de Bobastro"(IBN HAYYĀN 198I: p. 57).

Nótese que se habla de innumerables fortalezas de la cora de Elvira, pero sólo se menciona la más importante, la de Juviles. Son muchas las que escapan al autor de la Crónica, que posiblemente no conoce o bien no le interesan. Normalmente sólo se hallan citadas aquéllas en las que hay o luego habrá 
un alcaide puesto por el poder estatal. Es obvio que se trata de una reducción interesada para hacer comprensible el proceso a quienes podían acceder a la fuente escrita en cuestión. No es menos cierto que se deriva de aquí un interés por marcar una jerarquización de los castillos, pues sólo uno es el principal, hasta el extremo que su caída es la más difícil y produce un ciego pavor a hombres de puntos alejados de él. En cualquier caso, se puede hacer una lectura en negativo; es decir, hay numerosos castillos que tienen diferente cualificación. Claro está que esto hay que comprobarlo a niveles arqueológicos.

Manuel Acién dibuja una panorámica sumamente interesante al respecto, partiendo del análisis de las fuentes. Menciona sociedades distintas, configurando un modelo diferente al de Guichard, en el que la dinámica es mayor y, en consecuencia, su complejidad es también de un grado superior: “...me atrevo a formular un esquema algo más complejo. En primer lugar, existe una formación social islámica cuyas características diferenciadoras serían la hegemonía de lo privado y el mundo urbano, representada en un primer momento por los miembros del Estado cordobés y unos escasos elementos, poblacionalmente hablando, oriundos del Hî̀āz o vinculados al Estado Omeya de Oriente. Junto con ellos, los nuevos pobladores, árabes y beréberes, traen consigo su organización social tribal. Finalmente, la sociedad indígena hispano-visigoda, al igual que la europea del momento, se encuentra en un claro proceso de feudalización. A partir de aquí se inicia una evolución compleja que podemos considerar como transición y que finaliza con el triunfo de la sociedad islámica hacia la época del califato, al menos en este "sur" de al-Andalus" (ACIÉN 1989: p. 142).

Este modelo se intenta materializar a partir de un primer análisis arqueológico. Los edificios castrales que se han ido identificando prueban una diversidad que, no sin cierta dificultad, se podrían asimilar a esa dinámica política previamente enunciada. De todas formas, falta un examen, que necesariamente ha de ser posterior a este esquema, detenido por territorios de los castillos. Ante todo, es pre- cedente definir las estructuras, porque la diversidad es muy importante. No cabe hablar de un solo edificio castral, modelo paradigmático de la sociedad andalusí. Es evidente, asimismo, que no se puede detener el análisis en una etapa concreta, porque los monumentos o estructuras arquitectónicas son elementos históricos que se desarrollan y transforman. No se puede detener el análisis arqueológico en un momento dado, prescindiendo de los demás.

La elaboración de estos modelos, evidentemente creados a partir de las fuentes escritas y de un examen aún elemental de los restos arqueológicos, son un primer paso, que no el último. Pero plantean de manera clara y evidente el tema del uso de la Arqueología y el tipo de la misma.

Se ha señalado frecuentemente que la Arqueología del paisaje o la extensiva es el método utilizado normalmente. No es posible, sin embargo, hacerlo sin contar con una elaboración más precisa. Este tipo de Arqueología corre el riesgo de ser bien la aplicación de una plantilla, bien de no superar una fase meramente descriptiva. A los riesgos puestos de manifiesto, hay que añadir el problema de la perdurabilidad de los asentamientos que se analizan, que no su inmutabilidad. De ahí la escasa posibilidad, sin realizar una excavación o una prospección muy minuciosa, de hacer precisiones cronológicas muy determinadas. Es más, ni es posible ni aconsejable adecuarlos a las realidades políticas.

Es absolutamente imprescindible desarrollar programas concretos, sin dejar a un lado obviamente los aspectos generales. Se puede decir que no hay suficientes trabajos sobre territorios concretos y específicos, aunque se hayan establecido ciertas pautas. En tal sentido, y desde luego teniendo como punto de referencia los modelos ya mencionados, cabe destacar la aportación de Patrice Cressier, centrada básicamente en la Alpujarra. Puede servir de ejemplo, pues habría que citar algunos más (BERTRAND 1990). En un importante trabajo sobre los castillos alpujarreños (CRESSIER 1984), encuentra confirmación 
del modelo de Guichard y señala que hay una pervivencia muy grande a lo largo del tiempo. Sin embargo, el análisis de las estructuras pone de manifiesto que hay diferencias entre unas y otras, a veces más marcadas de lo que el autor destaca. El artículo arranca, pues, del esquema previamente trazado, pero no puede ocultar que hay significativas distinciones.

En cualquier caso, es obvio que la subjección de estas fortalezas a un medio rural en el que la agricultura de regadío es primordial, destaca por encima de todo. Pero hay indicios de que no siempre es así. La visión de unos castillos dedicados a servir de refugio a los campesinos y sin mecanismos de dominación, salvo las relaciones en cierto modo episódicas con el Estado, no es completa y es una exageración por parte de los detractores del modelo que se ha ido creando, porque éste siempre ha de ser considerado como un punto de arranque.

Ya hemos dicho que los asentamientos y fortificaciones tienen un significado especial, pero también que hay una gran dificultad para su estudio. En cuanto a los primeros, si se recuerda lo afirmado por Barceló, hay que notar que las estructuras hidráulicas, de las que dependen y son deudores, han creado una gran rigidez, que hace imposible un cambio sin más. Por lo que respecta a las segundas, la perduración es evidente a lo largo del tiempo.

En el primer punto hay que hacer algunas afirmaciones que consideramos importantes. Los asentamientos rurales de época árabe son fruto de una gran transformación del medio físico que se articula en el regadío y los sistemas hidráulicos que lo permiten. En las fuentes escritas se puede ver cómo los árabes eran conscientes de que tenía que haber una seria modificación del medio para la instalación de una agricultura como la que traían. Es conocido el texto de al-Maqqarī, autor del siglo XVII, que recopila noticias anteriores de al-Andalus, en el que habla de la construcción de la ciudad palatina de Madīnat al-Zahrā' por 'Abd al-Rahmmān III, en el siglo X:
"Cuando al-Zahrā' se sentó en su salón y vio la blancura y belleza de la ciudad en el regazo de aquel monte negro, dijo al califa: " $O$ h mi señor! ¿Acaso no ves la belleza de esta muchacha en el regazo de ese negrazo?". Y al-Nāsir ordenó hacer desaparecer el monte, lo que escandalizó a sus cortesanos, que dijeron: "Lo que pretende el califa repugna a la razón, pues aunque se reunieran todas las criaturas del mundo a cavar y cortar, no lo lograría sino el propio Creador" Pero lo que hizo el califa fue ordenar que se cortasen los árboles del monte y que se plantasen en su lugar higueras y almendros. Y el paisaje se convirtió en el más bello del mundo, especialmente en el tiempo de la floración y brote de los árboles" (AL-MAQQARI 1988: p. 128).

La ciudad aparece, en una hermosa figura poética, como una doncella blanca en el regazo de un negro. El propio autor señala que la ciudad, blanca y bella, estaba rodeada por un monte negro y amenazante. Es la contraposición entre la refinada civilización de la madīna, nuevo centro del poder del califa, y el paraje en que se instaló, en donde el encinar pardo-oscuro e impenetrable rodeaba el bello conjunto urbano. En un medio natural en el que la ocupación humana no era fácil, se instalaba una ciudad, expresión máxima de la civilización. Así, señalada y remarcada la diferencia, ante las protestas de los hombres de religión, se opta por crear un espacio intermedio en el que la vegetación atenúa el violento contraste.

Esta imagen es la que tenemos de otros puntos especialmente en los centros del poder, que son los que mencionan más claramente las fuentes escritas. Es el caso de la Alhambra y sus áreas próximas, que se integran en todo el conjunto palatino, en los últimos siglos de al-Andalus. Conviven los elementos más refinados, en donde la naturaleza aparece de forma muy sofisticada en los jardines palatinos, pero al mismo tiempo hay huertos y tierras de regadío que abastecen a sus pobladores, y, más arriba, el monte. Existe un escalonamiento de vida vegetal, que permite la transición entre el mundo urbano y el natural, sin una gran violencia. 
El mundo rural en sentido estricto no nos es tan bien conocido como los espacios urbano y periurbanos, objeto de atención por los autores árabes. De todas formas, hay cuestiones que se pueden comprender a partir de la Arqueología del paisaje. Una característica de los asentamientos es que se imbrican con el medio físico, al que han transformado para crear un sistema hidráulico que permita el establecimiento de áreas de cultivo irrigadas. Hay, de un lado, una adaptación topográfica. Viene determinada por la necesidad de utilizar el agua, lógicamente movida por gravedad. De este modo, la pendiente es modificada, quebrándola por medio de terrazas de cultivo, y utilizada en beneficio de esta agricultura. La situación topográfica de los núcleos rurales ha dejado, pues, una huella muy fuerte en el paisaje. Es habitual que el asentamiento se sitúe encima del área de cultivo irrigada y por debajo del monte. Sin embargo, no es de menor importancia el mundo vegetal que se desarrolló en esa agricultura irrigada. No se puede hablar de adaptación topográfica sólo para intensificar unos cultivos ya conocidos. Se explica por la adopción de un nuevo ecosistema en el sentido más claro del término. La vida agrícola generada muestra que las plantas crecen con frecuencia en la época de calor, necesitando un aporte hídrico muy superior al que le proporciona el seco clima mediterráneo. En consecuencia, las tierras están en uso permanentemente. El nuevo ecosistema se implantó a partir de la alteración y a costa del anterior, con el que además convive. Los problemas que se derivan de esta situación apenas han sido estudiados. Deberán realizarse no sólo desde una perspectiva descriptiva o morfológica, sino haciendo cuantos análisis y estudios sean precisos. Así pues, es urgente, de un lado, documentar las plantas que se introdujeron y verificar, siempre que sea posible, su difusión en los campos. No se puede mantener la imagen de una agricultura sólo de jardines, en los que se experimentan injertos y se adaptan nuevos vegetales. La extensión de los cultivos ha de ser mostrada con pruebas irrefutables, entre ellas las derivadas de la antracología, palinología y carpología. Tampoco se puede prescindir de las referencias anotadas en las fuentes escritas, siempre que sean un punto de apoyo y no un fin en sí mismas. Asimismo es necesario conocer las técnicas constructivas de las terrazas y el desarrollo de las mismas. En ese sentido, la excavación reciente de una necrópolis tardorromana en el Cortijo de Ana, en Pago (Orgiva, provincia de Granada), ha obligado a establecer una estrategia en ese sentido. En el caso concreto que mencionamos se puede decir que es de vital importancia conocer la formación de la terraza de cultivo que hay encima de dicha necrópolis, y su uso, porque permitirá establecer cómo se generó el área irrigada luego del abandono de aquélla.

Estas estructuras de poblamiento, regidas por una agricultura intensiva de regadío, tienen una gran fuerza de cohesión social, que, a su vez, es generada por la inexistencia de señores territoriales y por unas relaciones muy laxas con el Estado. La perduración está asegurada. Sólo correrá riesgos cuando se produzca el establecimiento de poblaciones alóctonas, regidas por otros principios sociales y económicos. De todas formas, por lo que sabemos hasta el presente, se emplearon, al menos en el reino de Granada, que es el campo en donde se han elaborado propuestas de análisis al respecto y se han estudiado territorios, diferentes estrategias de ocupación de estos espacios (TRILLO en prensa 3). Por un lado, tenemos la desaparición de las áreas de regadío y de la estructuras de habitat que las generaron y mantuvieron, pero también se conservaron e incluso se ampliaron. Se debe a la necesidad de desarrollar unas especies vegetales que tenían una gran salida en el mercado de productos en los años

8 A este respecto deben de considerarse los trabajos de TRILLO SAN JOSÉ, C.: "Las especies vegetales en el reino de Granada al final de la Edad Media, según el vocabulario de Pedro de Alcalá (siglos XV-XVI)". Formas de habitar e alimentação no Sul da Peninsula Iberica na Idade Media. Mértola, 1993 (en prensa), y “La vegetación en el reino de Granada en el tránsito de la época medieval a la moderna, según el vocabulario del Padre Guadix". Coloquio internacional: Transformaciones agrarias y cultura material en Andalucía Oriental y Norte de Marruecos. Granada, 1994 (en prensa). 
finales de la Edad Media. Por ello, aun cuando hubo una despoblación de algunos asentamientos, siguieron funcionando agrícolamente, con gentes de núcleos próximos. Es el caso que hemos estudiado de Gualchos, en la Costa de Granada (MALPICA 199la), en donde, como en otros puntos más o menos próximos, seguía en pie el conjunto productivo, bien que seleccionando las especies cultivadas, que suelen ser árboles, menos difíciles de cuidar.

Esta perduración de los asentamientos no exime de un estudio más detenido de los mismos, a partir de una actuación arqueológica rigurosa. Significa la generalización de la excavación, pero también de la prospección meticulosa. Así, cuando frecuentemente se hace un análisis somero de los espacios cultivados, se abandona una información arqueológica de primera magnitud, como se ha visto en el caso de la vega de Órgiva, concretamente en el Cortijo de Ana, en Pago. La seducción por los despoblados es legítima, pero sólo desde una perspectiva de una Arqueología en el sentido más clásico del término, porque suelen ser elementos fosilizados, que se han detenido en una época concreta, alterados por procesos potsdeposicionales, ya antrópicos, ya geomorfológicos. Cuando se aplica una Arqueología del paisaje se debe realizar una investigación a fondo en los núcleos habitados y en las tierras cultivadas que se relacionan con ellos. Sólo de esta forma cabe hablar de perdurabilidad, pero no de inmutabilidad.

Los castillos presentan otras características dignas de destacarse. De todos es conocido que se tratan de estructuras realizadas para perdurar. Su situación permite asimismo su mantenimiento, porque se establecen en puntos elevados, lejos de los espacios cultivados, por lo general equidistantes de los núcleos de habitación. Son obras fuertes, como parece lógico, que deben cumplir misiones de protección, y que son apropiadas por el poder político o el Estado, o generadas por él. No es por ello extraño que presenten claras innovaciones arquitec- tónicas que determinan su adscripción, como se aprecia en los castillos nazaríes, según ha puesto de relieve Manuel Acién (ACIÉN en prensa). En ese sentido, es normal encontrar inscripciones epigráficas que refuerzan el sentido estatal del castillo. Es obvio, por lo demás, que la reutilización de edificios anteriores es hasta cierto punto habitual, según se observa en muchos de ellos. El propio Acién lo ha puesto de relieve para el caso de los castillos utilizados por el califato (ACIÉN 1992). Por eso, el análisis de los restos arqueológicos obliga a un estudio muy pormenorizado de las estructuras elevadas y de la cerámica recogida en superficie, caso de no ser excavados. La experiencia nos ha mostrado que es fundamental para comprender no sólo el edificio, su evolución y funciones, sino también la relación con el territorio. Los cambios de las estructuras e incluso de las técnicas constructivas son índices a tener en cuenta.

En cualquier caso, es evidente que incluso en una misma época hay una gran diversidad de estructuras, que muestran una lógica diferencia de funciones. No obstante, es preciso volver a recordar que se reutilizan y readaptan muchas fortalezas anteriores.

Conviene poner de relieve, llegados a este punto, que el mismo poder político ha ido seleccionando las estructuras arquitectónicas. Unos edificios se conservan casi perfectamente y fueron dotados de un papel primordial para sus intereses, mientras que otros apenas han dejado huella. Se trata sobre todo de los que eran sólo unos refugios eventuales y que no fueron reaprovechados posteriormente. Al estar, por lo común, situados en puntos elevados y con un relieve abrupto, han sufrido un proceso de erosión que ha generado problemas de reconocimiento y evaluación de su extensión y funcionalidad.

De todas maneras, el esquema trazado hasta aquí necesariamente ha de completarse. Aunque la vida agrícola era esencial en al-Andalus, con las lógicas modificaciones en el transcurso del tiempo, no era la única 
actividad económica. Se debe hablar del aprovechamiento de los recursos naturales, muy importantes, pero sobre cuya utilización económica casi no sabemos nada. Nos referimos, por ejemplo, a las explotaciones mineras y a otras también de tipo extractivo, como las salinas. Es evidente que la situación de determinados castillos, e incluso su relación con alquerías, lo pone de relieve. En los castillos del Marquesado del Cenete, en la cara $\mathrm{N}$ de Sierra Nevada, y en algunos de la vertiente $\mathrm{S}$, o sea de la Alpujarra, se aprecia con mayor o menor claridad que la minería e incluso los procesos de tratamiento del mineral tenían lugar en su territorio. El castillo de Alquife es uno de los mejores ejemplos, pero aún no ha sido estudiado, desgraciadamente. Tal vez se deba a que hasta ahora el modelo que se ha analizado ha sido el agrícola en sentido estricto. Sin embargo, los metales monetizables (singularmente plata y cobre) debieron de ser objeto de un control muy riguroso; en menor medida el hierro, más fácil de elaborar y más abundante.

También hay estructuras defensivas en territorios en los que la riqueza en sal era muy importante. La explotación de las salinas, vital para la ganadería y la alimentación, tendía a ser controlada y protegida, que en éste, como en otros casos, era una misma cosa. En un somero análisis sobre el castillo de Peñaflor, apoyándose esencialmente en una referencia en las fuentes escritas y en el hecho de que se hallaba en torno a una zona salinera, Vicente Salvatierra advirtió de esa posibilidad (SALVATIERRA 1990).

Parece claro que es necesario examinar territorios más o menos coherentes, que muestren la regularidad de su ocupación y pongan en tensión el modelo teórico que se ha venido elaborando. De otra manera, sólo se llegará a aplicar con unos resultados muy pobres. Por nuestra parte parece oportuno que hagamos un balance del proyecto arqueológico desarrollado en una zona concreta de la actual provincia de Granada, al S, la Costa.

\section{EL ANÁLISIS ARQUEOLÓGICO E HISTÓRICO DE UN TERRITORIO: EL EJEMPLO DE LA COSTA DE GRA- NADA.}

A partir de 1985 se ha llevado a cabo un proyecto de investigación financiado y autorizado por la Dirección General de Bienes Culturales de la Junta de Andalucía. Tenía por título Análisis de las secuencias del poblamiento medieval de la costa granadina. Aunque su primordial interés estaba en conocer el poblamiento medieval, bien pronto se demostró que no era posible ignorar otras etapas. La propuesta surgió de un estudio eminentemente basado en un primer análisis de las fuentes escritas. Rápidamente mostró su incapacidad para resolver determinadas cuestiones, especialmente las derivadas del proceso de destrucción de la sociedad vencida por la conquistadora, a finales de la Edad Media. Es verdad que este estado previo de conocimientos, procedente del análisis de la documentación escrita de época castellana, permitía una aproximación a las formas de poblamiento de la etapa precedente, la nazarí. Sin embargo, del estudio de la mismas fuentes escritas se infería que la actuación de los castellanos había dado lugar a toda una serie de transformaciones que comenzaban a desdibujar e incluso ocultar la organización del poblamiento precedente. Además, el carácter selectivo de esta documentación no dejaba ver con suficiente precisión la existencia de elementos primordiales en la estructura del poblamiento andalusí, que no lo eran tanto para la que se estaba implantando. El proceso de aculturación fue muy intenso y ocasionó éste y otros problemas. En efecto, en las formas de organizar el territorio en las etapas finales del mundo andalusí, se incluía el de los orígenes de éste. Las referencias escritas de época islámica resultaban insuficientes. Por eso, una de las cuestiones a las que desde un principio se necesitaba dar una respuesta, era explicar el poblamiento medieval y su relación y diferencias con el de épocas precedentes, sobre todo, como es lógico, la inmediatamente anterior, la romana. Se pretendía comprender los distintos modelos de organización de la estructura de poblamiento y conocer los cambios habidos de unas a otras 
épocas. Así, la Arqueología en sentido amplio era imprescindible; sin ella, sólo se podían conocer elementos aislados de un proceso complejo, en el que aparecían a través de las fuentes escritas especialmente los momentos de conflicto de las poblaciones con el Estado.

La definición física de la costa es el punto de partida obligado. Limitada por la cadena montañosa que la cierra al $\mathrm{N}$, se abre al mar Mediterráneo que siempre ha sido su principal vía de comunicación. Apoyada en la montaña y de cara al mar, ambos elementos le han dado a este conjunto una personalidad muy marcada. Pese a estar separada de la alta montaña, como es Sierra Nevada, por el profundo surco del Guadalfeo, se aprovecha de ella porque una buena parte de sus aguas las recoge este río, el único que merece tal nombre de todos los que hay en la zona, puesto que más al $\mathrm{O}$, el río Verde, el Seco y el Jate sólo llevan agua de forma ocasional, gracias a las resurgencias de las masas calizas de la Almijara. El Guadalfeo, sin embargo, se provee del deshielo de la Sierra Nevada, pero también de las lluvias que recogen las cumbres menos elevadas. Hasta pasar el denominado Tajo de los Vados no se llega a la llanura litoral que conocemos actualmente como vega de Salobreña-Motril. Es la más extensa de cuantas existen en la costa de Granada. Más al E el medio calizo de Sierra de Lújar y el esquistoso de la Contraviesa han formado diferentes llanuras, apenas extendidas, por las que casi no discurren aguas superficiales, aunque en aquélla hay capas freáticas importantes.

La alternancia de relieves diferentes, con un medio litológico muy distinto, ha dado lugar a unos paisajes muy peculiares que han condicionado y consentido los asentamientos humanos. En los medios calizos, más abruptos y con barrancos muy encajados, la ocupación es difícil; en los restantes es más fácil. Especialmente importante lo es en torno a las llanuras costeras.

En lo que respecta a su base física es una zona inclinada al mar y elevada. Apenas se puede hablar de tierras llanas, salvo en unas pocas áreas y siempre a las orillas del mar. Este siempre ha sido un importante elemento regulador de las temperaturas y generador de hume- dad, por no hablar de las posibilidades de comunicación con el exterior que ha ofrecido a lo largo del tiempo. También la cadena montañosa costera, muy próxima a la línea marítima y orientada en esa dirección, ha impuesto su ley. Las elevaciones son importantes; la pendiente es una abrumadora realidad, hasta el punto que la relación entre las áreas interiores y las próximas al mar se ha regido por ella. La vida humana ha quedado regulada por su existencia. Los cursos de agua, que bajan muy encajados por los valles transversales al eje montañoso, han generado grandes aluvionamientos al llegar a la costa. La deforestación es la gran responsable; en los últimos siglos se acentuó, concretamente desde el siglo XVI hasta la actualidad hay numerosos testimonios en las fuentes escritas que lo avalan. Se formaron llanuras costeras por aluvionamientos, sin apenas influencia marina. En todos los casos, por lo que sabemos hasta ahora (HOFFMAN 1988), las tierras bajas han crecido a partir del deterioro de las altas, especialmente debido a las ya mencionadas desforestaciones.

El comportamiento de los suelos ha sido diferente. En cuanto a los detríticos, se formaron por la destrucción de la capa vegetal y el posterior arraste de tierra. Los procedentes de un medio calizo se han ido deteriorando hasta el extremo de quedar la roca desnuda, mientras que las alteraciones de las rocas metamórficas (sobre todo esquistos, micasquistos y filitas) han dado lugar a una fuerte degradación de la roca madre, formándose suelos con piedras gruesas, fruto de alteraciones mecánicas. Deberíamos hablar también de las posibilidades hídricas de cada uno de ellos. En los calizos apenas hay escorrentía superficial, pero se forman mantos freáticos; en los esquistos, al ser impermeables, existe una circulación hídrica de superficie. Ahora bien, no hay un medio litológico único, aunque encontremos el predominio de uno u otro en cada área. Existe una adaptación a cada uno de ellos en un medio geográfico limitado. Se observa como regla general la ocupación agrícola de las tierras de rocas metamórficas, en tanto que en las calizas se establecieron los asentamientos. En realidad, la mayoría de los núcleos, desde luego en época medieval, se hallan en la zona de contacto entre las calizas y los esquistos, en donde se hallan las fuentes de resurgencia. 
El establecimiento de los asentamientos medievales en ese medio, que hubo de ser transformado, supuso de manera inmediata la generación de un sistema agrícola muy peculiar. Se basa en la creación de un ecosistema propio, aunque adaptado. En él es fundamental el agua, utilizada para irrigar las tierras de cultivo.

Seguramente se estableció este sistema a lo largo de un proceso extenso y discontinuo, que parece alcanzar su cenit con la consolidación del Estado islámico, que, lógicamente, acelera unas tendencias y modifica otras. Este proceso cristalizó luego de una larga transición en la que diferentes modos de producción se enfrentaron. Políticamente se plasma, a través del Estado, en la organización espacial del poblamiento, en el territorio; pero no sólo nos habla de esto, sino de los mecanismos de dominación social y económica. A esta cuestión, entre otras, era a la que debía de responder la investigación.

Nuestro proyecto se planteó, desde el principio, con desigual intensidad para el conjunto de la costa granadina. Se prefirió un acercamiento a diferentes niveles, teniendo en cuenta las necesidades que había. Dos técnicas eminentemente arqueológicas se desarrollaron, siempre para resolver problemas históricos, algunos de los cuales surgieron en su propio desarrollo. Fueron la prospección arqueológica y la excavación.

\section{La prospección arqueológica de superficie.}

Se intentaba, a partir de ella, analizar las secuencias del poblamiento medieval en la zona costera de Granada?. Esta se dividió en varios sectores, que coincidían, aproximadamente, con los territorios que se habían identificado en los últimos tiempos del mundo nazarí. En concreto eran: a) el área del río Jate y del Verde, nucleada en torno a la ciudad de Almuñécar, ocupada desde la Antigüedad; b) el valle bajo del Guadalfeo, integrado por varios subconjuntos, pero con un centro rector en su vega, Salobreña; c) la Sierra de Lújar, imponente mole caliza que se levanta frente al mar, en cuya cara $S$, aunque también en la parte NE, se encontraban diferentes alquerías que se agrupaban en la țā́a de Suhayl, y d) la Sierra de la Contraviesa, que estaba contigua, denominada țā́a de Sāhil.

\section{La excavación sistemática.}

Se quería hacer un estudio de mayor profundidad, centrado en un área más reducida y a partir de un yacimiento concreto a excavar. Se eligió el valle del río de la Toba, es decir, el subconjunto de Los Guájares. El punto de partida era la excavación sistemática del yacimiento de "El Castillejo", un asentamiento fortificado de época medieval concretamente almohade- nazaríi ${ }^{10}$. Está situado frente a la actual localidad de Guájar-Faragüit y por encima de la de Guájar-Fondón. Pero era preciso plantear y resolver una serie de cuestiones relacionadas con la dinámica del poblamiento en todo el valle y la transformación ecológica de una zona de montaña, que parecía ser el principio de la organización del territorio en época andalusí, por el establecimiento de áreas irrigadas dependientes de núcleos de poblamiento rural. Se planteaba de este modo el estudio de tales unidades de poblamiento a partir de una focalización en un yacimiento concreto, para establecer una estratigrafía y, en consecuencia, unas cronologías. El análisis de los asentamientos a partir de la prospección hidráulica, partiendo siempre de una clara conexión con el yacimiento de "El Castillejo", debía de desarrollarse como una investigación particularmente significativa".

\footnotetext{
9 Esta parte del proyecto se desarrolló bajo la dirección de. MALPICA CUELLO, A (Dpto. de Historia Medieval de la Universidad de Granada) y MARÍN DÍAZ, N. (Dpto. de Historia Antigua de la Universidad de Granada).

10 Excavación dirigida por A. MALPICA CUELLO (Universidad de Granada), P. CRESSIER (Casa de Velázquez) y G. ROSELLÓBORDOY (Museu de Mallorca).

II Programa de investigación desarrollado bajo la dirección de Miqel BARCELÓ (Universidad Autónoma de Barcelona). Un avance del mismo en BARCELÓ, M.: "La arqueología extensiva y el estudio de la creación del espacio rural", en BARCELÓ, M. y otros: Arqueología medieval. En las afueras del medievalismo, Barcelona, 1988, pp. 25I-255.
} 
El proyecto quedaba, sin embargo, abierto a otras acciones necesarias y que fueran consideradas oportunas y obligadas. Así, se llevaron a cabo algunas intervenciones de urgencia, que permitieron al menos dos cosas: en primer lugar, ampliar el campo de análisis, $y$, en segundo lugar, plantear problemas nuevos, que sólo podían surgir del trabajo arqueológico. Así, la realidad aplastante de una transformación casi diaria se imponía y obligaba a entrar en una dinámica propia de la Arqueología de salvamento. Se transformaban los presupuestos de partida y se tenía una nueva dimensión. Las grandes y graves alteraciones de las áreas llanas y próximas al mar pusieron de manifiesto la existencia de asentamientos en la línea costera, que apenas eran conocidos. Aun así, no cabe duda que el balance no puede considerarse positivo. A la pérdida de restos arqueológicos, hay que añadir que el medio físico se ha ido modificando de tal manera que queda sesgada la lectura de los asentamientos y de la relación Hombre/Naturaleza. Sólo hay algunos elementos aislados y restos de paisajes tradicionales como auténticos relictos.

El proyecto de investigación, como queda dicho, tenía como soporte inicial un análisis de las fuentes escritas y del medio físico. El modelo de partida se estableció fundamentalmente en base al poblamiento que encontraron los castellanos al llegar a este territorio. Para conseguir un control efectivo del mismo, señalaron los espacios productivos y las estructuras defensivas que les importaban. La documentación tenía además una especificidad fiscal muy fuerte. En cualquier caso, se apreciaba que los elementos primordiales de la estructura de poblamiento eran los núcleos rurales y los castillos y otras fortificaciones. Pero tampoco cabía olvidar las ciudades. Claro está que la presencia de estos asentamientos urbanos marcaba una gran diferencia entre las áreas occidentales y las orientales. En aquéllas la vida urbana tenía un peso específico muy fuerte, mientras que en las țā́as de Suhayl y Sāhil no se articulaba el espacio en torno a las ciudades. Esta distinción queda claramente expresada cuando los castellanos se establecen en este conjunto territorial. Las antiguas mudūn (plural de madina) sirvieron de punto de apoyo para penetrar en los territorios próximos y generar un poblamiento propio. Mientras tanto, las áreas sin ciudades propiamente dichas, tuvieron que ser controladas a partir de las fortificaciones existentes en la misma línea de costa, creadas para la defensa del litoral, pero también para evitar la penetración desde el mar hacia el interior. Esta distinción, además de poder explicarse tal vez por poblamientos diversos, ha de ser planteada por las diferentes formas físicas del espacio geográfico. Las áreas occidentales tienen hoyas litorales más extensas y fácilmente regables, mientras que en las orientales la costa es más quebrada e impenetrable, los cursos de agua son más irregulares y las comunicaciones muy difíciles.

Tal diferenciación sigue operando y tiene repercusiones en la propia investigación arqueológica. Las tierras llanas y próximas al mar son las más desarrolladas en los últimos tiempos, con una gran incidencia, según ya se ha señalado, en el paisaje y, cómo no, en los yacimientos arqueológicos. Es mayor, lógicamente, en las áreas occidentales que en las orientales, en donde la escasez de espacios llanos es evidente. Si tenemos en cuenta que sólo en las décadas finales se ha producido esta situación conflictiva, habrá que anotar que las consecuencias se han dejado sentir especialmente en la parte occidental costera con mayor fuerza. Si tenemos en cuenta esta tendencia, las posibilidades de investigación se hallaban muy mediatizadas.

En efecto, de un lado, las grandes alteraciones que se derivan del proceso de especulación de suelos para la construcción turística y para una agricultura muy intensiva, $y$, de otro, la especial forma de los asentamientos, de los que teníamos una imagen muy clara sólo a partir de las fuentes escritas, han condicionado los puntos de partida del trabajo de investigación. En buena medida han tenido que revisarse a lo largo de su desarrollo.

Como se verá más adelante, el territorio costero granadino tenía un poblamiento con unos núcleos rurales elementales, las 
alquerías, que se organizaban en torno a espacios más o menos extensos. En ellas la vida agrícola era esencial, siendo el regadío la parte fundamental del área de cultivo. Las tierras situadas en torno al valle del Guadalfeo y más hacia el $\bigcirc$, se articulaban con ciudades (Salobreña y Almuñécar), con las que mantenían unas relaciones en las que el papel principal, que no único ni aplastante, correspondía a éstas. La penetración de las mudūn en la vida rural es un hecho incuestionable. Sin embargo, la alquerías siguen teniendo una autonomía real, pues conservan en gran medida el control de los procesos productivos y tienen en ellas una fuerte presencia las instituciones de autogobierno. Es más, en aquellas partes en las que las ciudades no existían, el control del territorio sólo era posible a través de las fortalezas, que, como se verá, no tenían un peso específico grande en la relación con los núcleos rurales.

De todo lo dicho es fácil derivar que la penetración de los castellanos y su acción en el territorio siguió una serie de grandes líneas tendenciales. Ante todo, hubo un reforzamiento general de los sistemas defensivos, especialmente de los que había en la misma línea costera, tanto los conectados con una ciudad (alcazabas urbanas), como los aislados en el territorio. Asimismo se dio, siempre que fue posible, un poblamiento con hombres traídos de fuera, claro está que a partir de un punto fuerte y fragmentando los territorios preexistentes, entregando tierras y alquerías enteras a señores castellanos. Esto supuso, evidentemente, una modificación muy notable de las relaciones entre los centros ocupados (ciudades o castillos) y los núcleos rurales, acentuándose el carácter militar de aquéllos. En realidad, la costa de Granada se convirtió a finales de la Edad Media en una verdadera "frontera". La despoblación y la reducción de los asentamienos agrícolas fue la nota más llamativa en cuanto al resultado de la ocupación castellana y su política repobladora.

A partir de esta problemática se organizó el análisis arqueológico del territorio con una base fundamental en la prospección arqueológica superficial. Eramos conscientes, como queda dicho más arriba, que a las dificultades y a los problemas ya reseñados, había que añadir otros. En efecto, los núcleos urbanos, en todos los casos pluriestratigráficos, estaban sometidos a una presión constructiva casi intolerable, según se ha mostrado posteriormente, por una coincidencia angustiosa entre una agricultura intensiva, que demandaba una enorme cantidad de agua y por el peso sofocante de un turismo estacional de escasísima rentabilidad a medio y largo plazo. Las actuaciones arqueológicas debían de esperar la oportunidad, pero la rapidez de las transformaciones de las tierras periféricas lo impedía; además, lo que podríamos denominar núcleo histórico, e incluso las fortificaciones urbanas, o estaban ya totalmente alteradas, o caminaban de forma imparable a su radical transformación. El ejemplo del castillo de Salobreña es singular, puesto que su restauración se ha acometido por dos veces en décadas anteriores, sin análisis arqueológico de ningún tipo, y, lo que es mucho peor, sin disponer de áreas no removidas para poder excavar en ellas. La concepción de estos edificios como puntos de atracción turística, llevaba por el mismo camino al hermoso ejemplar de la fortaleza urbana de Almuñécar. Sólo algunos avatares políticos por el momento han detenido o, mejor dicho, frenado tal proceso.

Mientras esto pasaba con las ciudades, los castillos no urbanos se habían abandonado y se hallaban en ruinas. Teniendo en cuenta que la erosión es muy fuerte y que se hallan normalmente en puntos elevados en donde la pendiente es importante, la pérdida de información está asegurada.

Por su parte, los asentamientos rurales, según ya decíamos anteriormente, se han establecido por una modificación del medio físico basada en la generación de un nuevo ecosistema en el que la irrigación es fundamental. Las líneas tendenciales de un hiperdesarrollo de las áreas irrigadas, que han asegurado y siguen asegurando una producción agrícola intensiva, ha motivado un avance de las mismas y la consiguiente pérdida de restos arqueológicos. Sólo los lugares que han sido abandonados permiten un análisis más fácil. 
Decimos esto porque es posible incluso un estudio de las localidades ocupadas por medio de un método regresivo, aunque aún no ha mostrado todas sus posibilidades.

Las dificultades para una aproximación a la realidad arqueológica de la costa granadina eran, pues, significativas. De todas formas, si simplificamos las categorías de los elementos que conforman la estructura de poblamiento y sobre los que se ha podido hacer un primer análisis arqueológico a través de la prospección de superficie, hemos de hablar de castillos y de asentamientos rurales. Es evidente que se trata de una visión esquemática, pero operativa a efectos puramente expositivos. Hay numerosos casos en los que las diferencias son muy escasas o prácticamente desaparecen. De cualquier forma, parece un esquema válido para aproximarnos a la realidad del poblamiento medieval en la costa de Granada. Dejamos a un lado, sin embargo, las estructuras urbanas, que sólo han sido objeto de un análisis muy general e inspirado en las fuentes escritas, habida cuenta de que hasta hace muy poco tiempo no se han llevado a cabo intervenciones arqueológicas, dentro sobre todo de un nuevo programa de Arqueologia urbana. En todo caso, es obligado una mención aunque sea mínima a las ciudades.

\section{I.- Los castillos.}

El estudio de los castillos, sobre todo los rurales, ha generado una importante bibliografía, pues su análisis ha servido, incluso de punto de partida para estudiar la sociedad andalusí, marcando diferencias con la feudal. Anteriormente ya hemos hecho un análisis de los modelos que se han creado, como también del debate que se ha generado. Nuestro estudio arqueológico de los castillos de la costa granadina, como no podía ser menos, estuvo condicionado al principio por ese debate. La primera aproximación a los husșūn de la zona llevaba a comprobar las semejanzas existentes con el modelo de Guichard, sobre todo para los situados en las țācas de Sāhil y Suhayl (MALPICA 1986a).
Se identificaron y prospectaron en una fase inicial diversos castillos en el área interior de la Alpujarra costera. Así, el de Olías, en plena Sierra Lújar, término municipal de Órgiva, el de la Rambla del Valenciano (Sorvilán) y, ya en el extremo NE de la Contraviesa, el de Juliana (Murtas), aparecían como elementos fundamentales para la organización del poblamiento rural. Si observamos las alquerías documentadas a finales de la Edad Media, es evidente que los asentamientos tienen una relación espacial con los castillos existentes. Es decir, una fortificación pudo ser el punto de apoyo de una estructura de poblamiento. Claro está que eso no nos obliga a pensar que fuesen coincidentes en el tiempo. El análisis de los castillos permite una cronología más o menos segura, que puede ayudar al mismo tiempo a afinar la que nos ofrecen los habitats rurales que han seguido perviviendo. De ese modo, el estudio arqueológico de las estructuras castrales es muy importante, así como el de su distribución espacial y la cerámica en presencia.

Desde tales perspectivas, se puede decir que tanto la situación como las características constructivas de los castillos de la Rambla del Valenciano y Olías nos hacen creer que era prácticamente imposible el establecimiento permanente de un grupo humano de carácter militar. Se hallan en puntos de muy difícil acceso. Para llegar al castillejo de la Rambla del Valenciano es necesario recorrer un gran trecho por terrenos muy abruptos e incluso salvar una pared rocosa casi cortada a plomo. El de Olías se ubica en lo alto de un risco de la Sierra de Lújar, para subir hasta él se debe realizar un largo y penoso ascenso por un barranco. Aun cuando sabemos que el medio ha cambiado y se ha degradado notablemente, no parece que haya sido hasta el punto de que se haya convertido en algo tan agreste $y$ hostil. Por otra parte, es cierto que se han documentado restos constructivos, posiblemente de viviendas, en el interior del primero y en las proximidades del otro. Se podría pensar que hay que adscribirlas a una primera ocupación en época altomedieval, propia de un asentamiento de altura. Carecen, además, de estructuras defensivas de significación, 
reduciéndose éstas a algunos lienzos de muraIla. Por lo demás hoy sólo son muros de mampostería, base sin duda del tapial que se levantaría sobre ellos y se ha perdido. Dentro también del capítulo constructivo, hay asimismo que destacar la presencia de depósitos para agua: una cisterna en Olías y un aljibe bien construido y muy consistente en la Rambla del Valenciano. En ambos casos fueron hechos con la técnica de la țābiya. Todos estos elementos vendrían a apoyar la tesis de su utilización como husuūn refugio para la población campesina que viviera en los alrededores. La cerámica encontrada en la superficie de estos castillos permite asegurar su utilización cuando menos entre los siglos X-XI, es decir en el período califal y taifa, y posteriormente en época nazarí. En el último caso, hay que señalar que tal vez se trate de una ocupación ocasional posterior a la conquista castellana y como refugio defensivo.

Bastante distinto es el tercer castillo altomedieval que se halla en el sector oriental, el importante hișn de Juliana. Los restos que quedan y son visibles ponen de manifiesto su complejidad con respecto a los otros hușūn ya citados. Se sitúa en la margen izquierda de la rambla de Cojáyar, frente a la actual pequeña población de Mecina-Tedel (término municipal de Murtas). Se levanta sobre un espolón rocoso, por debajo del cual hoy pasa la carretera comarcal de Murtas a Ugíar. Aunque el relieve es escarpado por lo general, hay algunas zonas más llanas o amesetadas. Ocupa esta fortaleza un espacio de $180 \mathrm{~m} \times 120 \mathrm{~m}$. Una muralla, a veces muy enrasada, de tapial, aunque con una base de mampostería, rodea el conjunto, excepto en algunos puntos donde la roca sirve de mecanismo defensivo. Quedan tres torres de planta rectangular y diferente estado de conservación. La situada en el ángulo SE del conjunto fortificado, que es muy maciza y de un altura de cierta consideración, está deteriorada, porque ha sido parcialmente destruida para hacer un pequeño corral en su interior; se encuentra al mismo borde de la mencionada carretera comarcal. En el ángulo
$\mathrm{NO}$ se halla otra torre levantada sobre la misma roca, con una cimentación de mampostería, que sirve de apoyo al tapial; es de dimensiones más reducidas que las otra dos. La tercera torre está situada en el ángulo $\mathrm{N}$ $\mathrm{NE}$; es muy alta y maciza, siendo como las demás obra de tapial. Hay asimismo dos grandes aljibes situados a diferente altura. Son obra de hormigón con bóvedas de lajas de piedra unidas con mortero. El aljibe más alto se encuentra en una especie de meseta superior, en el ángulo NO. El otro, a media ladera, en la zona $\mathrm{E}$, tiene una característica muy peculiar: hay una base de ataifor, que se puede fechar en el siglo XI, incrustado en el hormigón de su pared exterior. Se pueden identificar asimismo otros restos de construcciones intramuros, como la de una suerte de parata situada en la parte intermedia de la subida, si bien lo más destacable son los posibles restos de una muralla interior, que posiblemente separaba la parte superior de la ladera. Quizás se trate de un recinto superior, separado del resto de la fortificación, hasta cierto punto identificable con una parte eminente o alcazaba, reservada para una función estrictamente militar, que, además está más reforzada que el resto. También podría pensarse que son restos de una fortaleza primitiva, anterior al amurallamiento de todo el espolón. En este sentido, hay que recordar que el aljibe que está en la parte más baja tiene en su hormigón restos de cerámica del siglo $\mathrm{Xl}$, aunque hay noticias en las fuentes desde fechas muy tempranas, que hablan de la existencia de una qarya en el siglo VIII. Esta cuestión, junto con la existencia de muros en el interior, ya mencionados, nos obliga a plantear la cuestión de la existencia de un asentamiento rural directamente relacionado con la fortaleza. En una plataforma caliza que se desarrolla al SE del castillo se ha podido hallar cerámica en su superficie. Es de la misma época que la encontrada en el interior del recinto. De todas formas, es evidente que a la llegada de los castellanos era un despoblado, porque en las fuentes escritas aparece Mecina-Tedel como alquería y Juliana como un espacio no habitado'2.

12 A.G. S., C.M.C., I época, leg. 131. 
Estas fortificaciones interiores son claramente representativas de una época determinada, en concreto la de formación del Estado islámico. Es por eso por lo que al menos la de Juliana aparece en las fuentes escritas, primero como alquería, más tarde como castillo, aunque puede que fuese ambas cosas, sobre todo cuando se habla de la instalación de un grupo humano árabe (SÁNCHEZ MARTíNEZ 1976: p. 60). De todas formas, no se debe olvidar que se han recogido fragmentos de cerámicas nazaríes en otros castillos. No sólo existen en el área oriental fortificaciones representativas de ese período tan complejo de la historia de alAndalus, el de la formación del Estado islámico, antes bien en la parte occidental las hay con similares características, sobre todo a la más compleja de Juliana.

Dejando a un lado las estructuras defensivas urbanas (alcazabas de Salobreña y Almuñécar), se debe hablar de tres hușūn, que de $O$ a E son: el Peñón de los Castillejos (Almuñécar), en el curso alto del río Jate, Moscaril (Almuñécar), por encima de Almuñécar y sobre el río Verde, y la fortificación de la cumbre de la Cuerda del Jaral (Molvízar), ya en la margen derecha del río Guadalfeo. Los dos primeros aparecen citados en las fuentes escritas, en el primer caso con cierta precisión. Aparecen mencionados en la campaña militar llevada a cabo por 'Abd alRaḥmān III contra el castillo de Jate o, por utilizar el término árabe, Šāt, que significa orilla, posiblemente en referencia a su situación en torno al río y no lejos del mar, y contra Moscaril. Se puede identificar aquél con el citado Peñón de los Castillejos, y éste con las ruinas existentes en el Pico del Pinar de Turillas. A partir de esa expedición, los problemas de la primera fitna terminaron en esta zona. Estos dos castillos, que en las fuentes aparecen vin- culados y estrechamente ligados entre sí, eran en aquellos momentos uno de los últimos bastiones del poder de los Banū Hafșūn'

El Peñón de Los Castillejos se encuentra situado en el extremo occidental del término de Almuñécar, en el mismo límite actual con la provincia de Málaga. Está en una elevación coronada por un imponente promontorio rocoso que domina la cuenca del río Jate, cerca del lugar hoy conocido como El Rescate. Se puede dividir, para una más fácil descripción, en tres zonas diferenciadas. En la primera y más baja, que se halla en una pendiente no muy pronunciada y rodeada por un corte de la roca, donde es posible advertir la presencia de restos de una muralla, se ven algunos muros de piedras apenas unidas por una argamasa, y se han podido recoger fragmentos de tejas. Son muestras de que el asentamiento era importante, más allá de la zona amurallada. Es posible que la referencia a los "arrabales" de Jate en las fuentes escri$\operatorname{tas}^{14}$ sea por la existencia de viviendas fuera del recinto amurallado. La segunda zona es la de acceso a la plataforma superior, a donde se llega pasando por varias rocas. En un estrecho paso se puede documentar una pequeña cisterna, que parecía que servía para recoger las aguas que llegaban desde la roca caliza superior, de donde mana eventualmente cuando hay lluvias. Finalmente en la plataforma superior, que debió servir como alcazaba, por seguir empleando los términos de las fuentes, o último reducto defensivo, se aprecian restos de dos lienzos de muralla de mampostería, que tal vez fuesen bases de muros de tapial; uno de ellos es posible que estuviera controlando y defendiendo el paso hacia la parte superior. Hay además dos aljibes, el más inferior encajado en una grieta de la roca y con un enlucido que recuerda el hormigón hidráulico roma-

\footnotetext{
13 Las referencias en las fuentes son abundantes. Vid. Una crónica anónima de 'Abd al-Rahmmān III an-Nāșir. Edición, traducción, notas e índices por LÉVI-PROVENÇAL, E. y GARCÍA-GÓMEZ, E. Madrid-Granada, 1950, pp. |40-|4|. Ibn HAYYĀN: Crónica del califa 'Abdarraḥmān III an-Nāșir entre los años 912 y 942 (al-Muqtabis V). Traduc. por VIGUERA, Ma J. y. CORRIENTE, F. Zaragoza, I98I, pp. 142-I43. Ibn 'DQAR̄̄ : Histoire de l'Afrique et de l'Espagne intituleé "al- Bayano'l-Mogrib". Trad. par FAGNAN, E. vol. II, Argel, 1901-1904, pp. 304-305.

14 "y desde allí cayó sobre Jete, fortaleza de las más inexpugnables, que rodeó y sitió hasta apoderarse de sus arrabales y dominar sus contornos, sin que le resistiera más que la alcazaba...' (Ibn H.AYYĀN |98| p. |42)
} 
no. Del superior no quedan restos de la bóveda, aunque se aprecia que está embutido en la roca, que debió ser cortada para tal fin. La cerámica que ha sido recogida en superficie abarca una cronología desde el siglo X hasta el XII.

Moscaril se sitúa encima de río Verde, al E de Jate. Desde él se ve incluso Almuñécar. Es de menor extensión y complejidad que el anterior, pero de una gran importancia en cuanto a su cronología y estructura. Está en una elevación caliza que domina el curso alto de río Verde, los llamados Pico del Pinar de Turillas y el de Moscaril. Se diferencian dos sectores. El más visible es el que está situado en la cima que se levanta en el extremo más oriental. Allí se puede identificar un pequeño recinto delimitado por muros de piedra seca - con escasa argamasa para unirla. En su ladera $\mathrm{S}$ hay también restos de muros, a veces enrasados, y abundantes fragmentos de tejas, lo que puede interpretarse como la existencia de un poblado. El otro sector se halla en la parte occidental, separada del anterior por una pequeña vaguada. Se conservan muros muy arrasados que prueban que había una torre de base rectangular y de mampostería, que unía sus piedras con mortero de cal, sin que se pueda precisar si era sólo la base, como parece lo más probable, de una estructura de tapial más elevada, hoy desaparecida. A partir de esta estructura se desarrolló otro recinto, defendido por dos muros de piedra seca, aunque hay que hablar también de que el mismo corte de la roca cumplía tales funciones defensivas. Todo parece indicar que nos encontramos ante elementos de dos conjuntos diferentes y que tal vez no se utilizaron tampoco al mismo tiempo. Aunque las fuentes mencionan a este hișn en el siglo $X$, en la campaña de Jate de 923, conducida por 'Abd al-Rahmān III, la cerámica recogida en superficie sólo nos ofrece una cronología para el primero de los sectores citados, entre los siglos VII-VIII, ya que en el segundo los fragmentos encontrados son insignificantes.
El tercero de estos castillos o estructuras defensivas es el de la Cuerda del Jaral. Se halla en una de las elevaciones orientales de la Sierra de Los Guájares, cerrando por el $\mathrm{N}$ la vega de Salobreña. Es un reducido recinto oval, rodeado por una muralla, de las que sólo nos queda su base de mampostería y que está incompleta. Es posible que tuviese también dos pequeñas torres rectangulares en sus extremos N y S. La cerámica de superficie va del siglo IX a comienzos del $\mathrm{X}$, es decir, cuando tuvo lugar el proceso final de formación del Estado islámico en al-Andalus.

Todo estos husūūn tienen unas características dignas de ser puestas de relieve. En todos los casos se abandonaron con toda seguridad en época nazarí. Ni la cerámica de superficie ni las referencias en las fuentes escritas permite pensar lo contrario. Es más, es posible que las fortificaciones de Moscaril y de la Cuerda del Jaral tal vez fueran destruidas luego de caer en manos del califa'. Hay otro aspecto sumamente importante: salvo Jate que tiene claramente un asentamiento, no es posible que las estructuras presentes permitan albergar un contingente más o menos numeroso de población. El poblado de Moscaril, sin embargo, es de una fase anterior, como suele suceder en algunos otros puntos, incluso de la zona $\mathrm{E}$, en donde un poblado de altura no fortificado debió de dar paso a una fortificación por elemental que fuese. Por si no fuera suficiente, hay que poner de relieve que carecen, una vez más con la excepción de Jate, de un elemento fundamental en los hușūn-refugio: una o varias cisternas para agua, que permitían una permanencia prolongada en caso preciso.

La importante presencia de la vida urbana es un dato a tener en cuenta en el área occidental de la costa granadina. En el siglo $X$, Almuñécar es considerada por las fuentes como una madina (BENECHERIFA 1986), en tanto que Salobreña no es calificada como tal hasta fechas posteriores, pero no cabe duda de que era una población destacada sobre el con-

15 Hay que anotar la ausencia de cerámicas califales, y por supuesto de épocas posteriores, y además sus estructuras constructivas se encuentran muy arrasadas. 
junto rural que la rodeaba (MALPICA 1992). Ambas tuvieron una rica vida urbana antes de la llegada de los árabes. La crisis que sufrieron en la tardía Antigüedad fue enorme y sólo pudieron tener una lenta recuperación, documentada arqueológicamente. En cualquier caso, sus respectivas alcazabas, ligadas directamente al poder político califal, tuvieron que ser determinantes en la adopción de un modelo de desarrollo del poblamiento. Se basaba éste sobre todo en las estructuras urbanas como puntos de defensa y en la existencia de alquerías campesinas sin mecanismos defensivos propios, salvo el de las ciudades. Esto no quiere decir que no subsistieran durante cierto tiempo algunos hușūn, como se aprecia en el caso de Jate, aunque quizás con características ya distintas.

Es evidente que las diferencias entre unos husūun y otros nos obliga a plantear la cuestión de diversas formas. Si volvemos al modelo que anteriormente se ha discutido, se podrá apreciar cómo el trabajo de Acién (ACIÉN 1989), puede servir de una primera pauta. Como se recordará, planteaba que durante la primera fitna en el $\mathrm{S}$ de al-Andalus se generaliza el encastillamiento de la población. No es un proceso que se deba de ligar únicamente a la acción política directa del Estado cordobés, sino que anteriormente ya se estaba produciendo. Hay que ponerlo en relación directa con el largo tránsito de la Tardía Antigüedad con la Alta Edad Media, que en el caso concreto de España y, desde luego, en nuestra zona, se hace más complejo por la llegada e instalación de contingentes árabe-bereberes. Poblaciones campesinas escaparon al control primero del Estado y, más tarde, de los grupos dominantes que pugnaban con hacerse con una renta extraída de ellas, rompiendo los mecanismos impositivos anteriores, que ya sólo eran un recuerdo (WICKHAM 1988).

Se puede advertir, pues, una situación en la que diferentes estructuras sociales luchaban por conseguir una hegemonía. La situación se complica con el establecimiento de los nuevos pobladores, que introduce un elemento distinto, la formación social islámica, que terminará imponiéndose. Ésta tuvo que desarrollarse en contra de las otras. Parece que en los distintos grupos de castillos se puede entender que hay una diferenciación clara de estructuras. Ahora bien, no hay que derivar de aquí una división mecánica, sino que se marca en ellos un proceso más complejo. Así, los asentamientos precedentes se pueden convertir en ummahāt alhusuūn, o castillos dependientes de señores (așhāb), que forman parte de grupos señorializados, en un proceso de captura de renta de las comunidades campesinas. Éstas tuvieron en algunos casos que reforzar sus propios mecanismos defensivos a partir a veces de sus primeros asentamientos de altura, creando husūnrefugios. Pero no cabe duda de que estas modificaciones no tienen una sola dirección, sino que se pueden detectar otras muchas. Los castillos creados por el Estado omeya o por grupos próximos a él se pueden basar en estructuras precedentes o incluso podrían devenir en mecanismos defensivos puestos al servicio de los grupos más señorializados, que no tienen una adscripción étnica, como se ha pretendido ver algunas veces, en contra de un análisis riguroso de las fuentes (ACIÉN 1994).

De este modo, es posible explicar las diferencias tipológicas ya señaladas entre unos y otros husūun de la zona de la costa de Granada. Se podría hablar de un primer grupo de castillos controlados por grupos señorializados y que no tardaron en enfrentarse al Estado cordobés. Parece que puede ser el caso de Jate. Su construcción no sólo, posiblemente ni siquiera de manera principal, debe interpretarse como una respuesta defensiva ante la acción del Estado, sino como un deseo de controlar, por un proceso lógico de concentración, a la población campesina en su interior. Su situación parece indicada para tal fin. Dominaba una rica zona agrícola, una de las más importantes de la costa, la cuenca del río Jate, sobre cuya producción los autores árabes nos hablan a lo largo del tiempo. ${ }^{16}$ Pero además no debe de olvidarse la

\footnotetext{
16 Como ejemplo se puede citar el texto del siglo XII de IDRĪSİ: Nuzhat al-muštāq. Edic. y traduc. DOZY, R. y de GOEJE, M. J.: Description de l'Afrique et de l'Espagne. Leyden, 1864-1866, pp. 198-199 del texto árabe.
} 
proximidad del puerto, Almuñécar, del que comenzamos a tener muestras de cierto desarrollo urbano entre finales del siglo IX y el siglo $X^{17}$, aunque en fechas anteriores estaba en funcionamiento como tal, sin que sepamos su grado de conservación, como lo demuestra el hecho de que allí desembarcara precisamente 'Abd al-Raḥmān I, el fundador de la dinastía omeya. También la ensenada de La Herradura servía como punto de desembarco ${ }^{18}$, aunque hasta el presente, pese a la proximidad con respecto al Peñón de los Castillejos, no se haya encontrado cerámica anterior al mundo nazarí. Este creciente empuje de la ciudad, ha de tenerse también en cuenta para explicar que Jete siguiera perviviendo y fuese uno de los castillos que mantuvo el poder omeya tras su victoria sobre las demás fuerzas sociales que se le oponían. Se muestra en el nombramiento de gobernador en 942 en lugar de "Wārit b. utumān b. Nūh de Jete, Salobreña y sus dependencias en favor de Sacid b. 'Abdalwāriț" (IBN HAYYĀN |981: p. 368).

Es probable que los otros dos hușūn, el de Moscaril y el de la Cuerda del Jaral estuviesen relacionados con Jate. La posible dependencia que se puede detectar es más bien consecuencia de un proceso posterior de reducción de fortalezas y de jerarquización del espacio a partir de una que es preminente y de las alcazabas urbanas. Tampoco cabe desechar la idea de que la ordenación de los castillos a partir del dominio de uno sobre los demás se llevase a cabo durante el largo proceso que venimos estudiando. Una cierta vinculación a Jate se deja entrever en las fuentes árabes. Ibn Hayyān, por ejemplo, señala que se rindieron otros castillos de la zona antes de tomar Jate (IBN HAYYĀN 198I: pp. | 42- |43). Esta posible red defensiva frente al Estado cordobés no puede enunciarse como tal en sentido estricto. Es posible que el juego de las alianzas de los grupos, estructurados posiblemente en linajes, permitiese acuerdos políticos, pero no una estructura permanente.

Juliana, en el área oriental, un hiș̣n bastante complejo puede incluirse entre los castillos bajo el dominio de los așhāa. La primera referencia al castillo, no así a la alquería, ya que se remonta a la primerísima época, en concreto al siglo VIII', aparece en el Muqtabas III de Ibn Hayyān (GURAIEB 1960 p. 318). Se menciona el enfrentamiento entre las tropas del emir 'Abd Allāh y los defensores del castillo, del que saldría victorioso el primero. Es un claro ejemplo de una estructura defensiva que se enfrenta al Estado omeya, en proceso de gestación. Se trata de un elemento bien organizado, como se ha visto en su descripción, que controlaría un territorio más o menos extenso, en relación con otros castillos y núcleos de población. Está, sin embargo, lejos de la zona costera occidental y posiblemente sin relación con ella. Parece que es obvio que no se trata del mismo grupo que se fortifica en la parte occidental; es más lógico que su origen estuviera en los árabes 'udrīes allí instalados durante el siglo VIII, a los que se refiere alUddrī, autor del siglo Xl, y de la misma tribu (SÁNCHEZ MARTíNEZ 1975: pp. 59-60). No debe olvidarse, sin embargo, que en torno a dicho castillo ha podido recogerse cerámica romana, que permite pensar en la existencia de un asentamiento de esa época, en consonancia con su topónimo.

En otro grupo, el de hușūn-refugios habría que incluir las dos fortificaciones ya citadas en la zona oriental: Olías y la Rambla del Valenciano. Numerosos datos, ya puestos de relieve, nos hablan de tal carácter, aunque hay que señalar algunas cuestiones del origen de ambas fortificaciones. Las dos, aunque espe-

17 En la actualidad ha comenzado un proyecto de investigación arqueológica urbana en Almuñecar, dirigido por el doctor Molina Fajardo, gracias al cual se está estudiando todo el material cerámico de excavaciones anteriores y se analizan las estructuras presentes en el actual entramado urbanístico y las que han sido desveladas a lo largo de diferentes intervenciones arqueológicas

18 En las Memorias de 'Abd Allāh, escritas en el siglo XI, se lee: "El caso es que envió sus galeras para atacar Almuñécar y Jete (Šàt) y que, a continuación, unas pequeñas fuerzas de caballería hicieron incursiones por aquellos territorios vecinos" (El Siglo XI en I ${ }^{a}$ persona. Las «Memorias» de 'Abd Allāh. Traduc. LÉVI-PROVENÇAL, É. y GARCÍA GÓMEZ, E. Madrid, 1980, p. I83.

19 Aparece en la obra de al-`Udrī, autor del siglo XI (SÁNCHEZ MARTíNEZ, M.: "La cora de Ilbīra (Granada y Almería en los siglos X y Xl, según al-`Udrī (I003-1085)”. Cuadernos de Historia del Islam, 7 (1975-1976), pp. 59-60. 
cialmente la de Olías, tienen restos de una etapa anterior a la plenamente califal. De la distribución de la cerámica de superficie se puede inferir, al menos de manera provisional, que las estructuras defensivas fueron creadas en torno al siglo $X$. En efecto, la cerámica califal aparece en sus proximidades, especialmente en las de los aljibes o cisternas existentes. Por el contrario, la que puede fecharse con anterioridad se halla próxima a las estructuras que se adscriben claramente al poblado. Es plausible que de una utilización como poblados en una etapa de tránsito del Mundo Antiguo al medieval, se pasase al establecimiento de una fortificación. Pero realmente no hay argumentos para precisar si tal actuación fue obra de las comunidades campesinas o de grupos ya ordenados jerárquicamente, aunque basados en el linaje y en la familia extensa, o una creación de señores. A nivel de una reflexión más profunda y, desde luego, posterior, hay que tener en cuenta que su configuración definitiva de estos enclaves como hușūn-refugios de alquerías ya plenamente formadas, es posterior, en concreto de los siglos X-Xl. Cuando ya están asentadas se percibe una corresponsabilidad defensiva entre el Estado y los núcleos de población. Puede ser un índice del papel que tuvieron tales comunidades en su erección.

En cuanto a fortificaciones construidas por el Estado no se han encontrado elementos que permitan hablar de su existencia en la costa de Granada. Pero de lo que no cabe duda alguna es de que el califato estableció una red defensiva apoyándose en estructuras preexistentes y es posible que incluso se construyesen algunas de menor entidad. Se percibe en la misma línea costera, mientras que en el interior no aparece sino una reutilización. Así se aprecia, como queda dicho, en el caso de Jate, del que ya hemos hablado acerca del nombramiento de un gobernador en 942, que era el mismo que el de Salobreña (IBN HAYYĀN 198।: p. 368). En esta última existía ya una de fortificación durante la primera fitna, como se aprecia en un texto de Ibn Hayyān, que dice lo siguiente:
"Viajó entonces an-Nāșir a la ciudad de Salobreña, donde hizo como en los lugares mencionados, guarneciendo, con sus hombres toda fortaleza que conquistaba y cuidando de sus intereses..."(IBN HAYYAN 1981: p. 62).

A todo ello se añade el establecimiento en Jate de un contingente de tropas pertenecientes al yund de Damasco, documentado en el 974. (GARCÍA GÓMEZ 1967)

Por lo que respecta a la construcción de nuevas estructuras defensivas, se observa que hay una política constructiva, apenas estudiada hasta el presente. Se debe esencialmente al hecho de que se pueden documentar en la misma línea de costa y en las fortalezas urbanas. Ese parece ser el caso del castillo de Almuñécar, según se empieza a vislumbrar en las actividades arqueológicas que están comenzando en esta ciudad. El caso de Salobreña, sin embargo, está por analizar; sólo diremos que la excavación del Peñón, que en época medieval era un islote frente a la ciudad, ha mostrado un material cerámico de época califal, que probaría una ocupación real del mismo en tales fechas, aunque no se han detectado estructuras defensivas. (ARTEAGA 1990)

Además de esas alcazabas urbanas, hay que plantear los elementos defensivos que parece que se levantaron en toda la costa. La excavación de urgencia realizada en 1990 en La Rijana (actual término municipal de Gualchos-Castell de Ferro), en la parte oriental de la costa, nos ha permitido datar entre finales del siglo $X$ y el XI la primeras construcciones existentes en este yacimiento. Es un edificio hecho de hormigón con abundante cal y piedra de la playa próxima, de planta rectangular. Se percibe como mínimo una división interna, pero no pudo investigarse a fondo, pues estaba en su interior prácticamente relleno. Se debe a la construcción de una torre de mampostería superpuesta a lo que ya era una plataforma, que se edificó en el siglo XVI. Esto ha impedido saber si se trataba de una construcción defensiva tipo torre o de otras características, levantada en fechas 
anteriores. En realidad, la excavación se desarrolló en gran parte de la zona superior rocosa que hay entre las calas de La Rijana, al $\bigcirc, y$ de Cala del Pino o Rijanilla, al E. Pero se documentó un conjunto defensivo, una especie de pequeño castillo, o recinto amurallado, que rodeaba toda la peña, que hay que fechar en época nazarí, dentro de un proceso conocido y general para toda la costa y seguramente de gran parte del reino, que supuso la fortificación de numerosos espacios. En todo caso, pese a que no se han podido extraer todos los datos deseables, es posible que tuviese una pequeña guarnición, posiblemente vinculada o dependiente del Estado, con el fin de poder controlar y proteger la navegación en este tramo de la costa. Ha de tenerse en cuenta que, como ya queda dicho, dos calas, una protegida del viento de Levante y la otra del Poniente, y la existencia de agua dulce casi al mismo borde de la orilla del mar, permitía que fuese un buen fondeadero para los barcos que por allí navegaban. Incluso se ha podido documentar la existencia de una estructura de época romana de planta rectangular, obra de mampostería y con un pavimento de opus signinum, que podría entenderse como una fuente dedicada a alguna divinidad. También podría cumplir esta pequeña fortificación la misión de servir de refugio a las poblaciones de los alrededores y a los hombres relacionados con las actividades pesqueras. Esto no implica que la meseta rocosa sobre la que se asienta se destinara a refugio ocasional de la población de los alrededores, en especial la relacionada con actividades marítimas. Aunque todo parece indicar que no es una fortificación inmediata al final de la fitna, y que incluso podría llevarse hasta el siglo Xl, es obvio que se inserta en un mismo proceso de consolidación del aparato estatal en la zona ${ }^{20}$.

El sistema defensivo situado en el interior montañoso no constituía el único, en la parte oriental, durante la época nazarí. Nos referimos a la presencia de una serie de puntos fortificados en la misma línea de costa. Se trataba de un sistema concebido desde el poder granadino para defender la costa, y no sólo ella, pues hay que pensar también en la protección necesaria a las actividades marítimas y comerciales. Estaba formado por una red de torres costeras, reformadas y ampliadas en número por los castellanos, contando, en el sector oriental, con un elemento central: el castillo de Castell de Ferro. No disponemos de un análisis arqueológico en profundidad del mismo, ya que hasta el momento sólo ha podido realizarse una prospección de superficie. Su actual estructura da idea de sus diferencias con los hușūn del interior de Sierra Lújar y la Contraviesa. Aunque las reformas cristianas y el estado de deterioro en el que se encuentra dificultan un análisis arqueológico de sus restos, parece que originariamente se trataba de una gran torre (tipo donjon) destinada al acuartelamiento de un grupo militar. La cerámica de superficie lleva a proponer que su construcción no debió ser anterior al siglo XIII, si bien sólo una intervención arqueológica más detenida podrá confirmar este extremo. Por otra parte, hay que apuntar la presencia de enclaves fortificados con vistas a servir de refugio en la misma costa y también en época nazarí, como se desprende de la actuación arqueológica llevada a cabo en la ensenada de la Rijana (Gualchos-Castell de Ferro).

Parece evidente que el sistema defensivo situado en la costa se superpuso al primero, aunque no lo eliminó (MALPICA y GÓMEZ BECERRA 1989). Ambos modelos convivieron durante la época nazarí: uno estrechamente ligado al poblamiento rural, el otro al poder granadino. La presencia de cerámicas de época nazarí en los tres castillos del interior lo demuestra claramente, si bien puede pensarse que la fortificación de la costa se realizó en detrimento de los castillos rurales, e incluso de las mismas comunidades campesinas que los sostenían (MALPICA y GÓMEZ BECERRA 1989: p. 254).

\footnotetext{
20 Sobre las actividades arqueológicas llevadas a cabo en la zona de la Rijana nos encontramos preparando una Memoria completa. Un adelanto de la misma puede verse en MALPICA CUELLO, A. y GÓMEZ BECERRA, A.: Una Cala que Ilaman la Rijana. Arqueología y Paisaje. Granada, |991.
} 
Como resumen de todo lo expuesto, puede afirmarse que el modelo propuesto a partir de los ejemplos levantinos, que recalcaba la existencia de castillos refugio para la población rural andalusí no es aplicable a todo el marco de la costa granadina por igual. Muy al contrario, los castillos rurales repartidos por nuestra área respondían en sus orígenes a modelos diferentes que, en último término, tienen su explicación en el complicado proceso de transición hacia la formación social islámica vivido en al-Andalus. Sin embargo, puede hablarse de una evolución posterior, en plena etapa islámica, que llevará a desdibujar el carácter original de algunos de ellos, como ocurre con Juliana, que al final encontramos utilizado como un hușūn-refugio más, o a la desaparición de otros, que es el caso de las fortificaciones levantadas en la parte occidental durante la fitna, tarde o temprano eliminadas por la consolidación de fortificaciones vinculadas al Estado islámico. Una evolución que no es ajena a los cambios apreciados en la ordenación del poblamiento en su conjunto y que ahora abordaremos a partir del análisis de los asentamientos.

\section{Los asentamientos medievales.}

Es imprescindible para analizar los asentamientos medievales que hemos prospectado dentro del proyecto Análisis de las secuencias del poblamiento medieval de la costa granadina, partir de una división amplia, aunque operativa. Para ello, creemos conveniente estudiar primero las denominadas alquerías de montaña y, posteriormente, las de las zonas llanas. En ambos casos el comportamiento de estos habitats es diferente en cuanto a la evolución posterior y, en consecuencia, a su conservación. Teniendo en cuenta que ya hemos hablado de los asentamientos asociados a fortificaciones (caso de Jate en el Peñón de los Castillejos y Juliana), no vamos a volver sobre ellos.

La complejidad de los asentamientos prospectados en el marco de este proyecto nos lleva a una división amplia, atendiendo en primer lugar a su encuadre cronológico, a partir del cual intentaremos poner de manifiesto algunas cuestiones referidas a su relación con el medio. Por otra parte, no entraremos de nuevo en el análisis de los asentamientos asociados directamente a algunos hușūn -el Peñón de Los Castillejos o Juliana- ni, por supuesto, en el más significativo de todos los poblados fortificados de esta zona, el Castillejo de Los Guájares

I. Los asentamientos de montaña, que no siempre podemos calificar de alquerías propiamente dichas, porque algunos no se identifican claramente con un habitat de tales características, es decir, no están claramente asociadas a áreas irrigadas de cultivo ni se integran en un territorio más o menos propio y definido, pueden dividirse, a su vez, en dos grupos.

En primer lugar, destacamos aquéllos que son anteriores a la época nazarí y que no parecen haber perdurado más allá de la formación del califato. Entre ellos, mencionamos tanto los que se hallan a media altura, como los más elevados, los denominados claramente habitats de altura.

De estos últimos podemos mencionar varios, situados algunos de ellos en cotas cercanas a los $1.000 \mathrm{~m}$. Se hallan a lo largo de toda la cadena montañosa, desde la Sierra Almijara hasta la Sierra de Lújar. En aquélla se localiza un asentamiento bien documentado, que ya hemos mencionado al hablar de los hușūn, el poblado de Pico Moscaril, en el actual término municipal de Almuñécar, en la cabecera de río Verde. Se trata de un asentamiento anterior a la fortificación que tuvo un papel relevante en las luchas que precedieron a la formación del califato. Quedan, como se dijo anteriormente, restos de construcciones, posiblemente viviendas en la ladera $\mathrm{S}$ del conjunto, en donde se ha recogido cerámica de época altomedieval y abundantes fragmentos de tejas. Es en Sierra Lújar donde hay más asentamientos de este tipo. Hay tres casos específicos a señalar: Pico Aguila (término municipal de Gualchos-Castell de Ferro), Picos del Castillejo (término municipal de Lújar) y el mencionado asentamiento asociado al castillo de Olías (término municipal de Orgiva). Son múltiples los problemas que plantean estos 
asentamientos. El primero es determinar su secuencia de ocupación. Aunque no es fácil, la cronología es más o menos precisa. El asentamiento del Pico Moscaril se sitúa entre los siglos VII y VIII. En Pico Aguila hay que hablar de dos momentos, uno correspondiente a los siglos VII-VIII, el otro entre finales del siglo IX y el $X$. Los Picos del Castillejo, aunque hay materiales posiblemente algo anteriores, debió estar ocupado en la etapa comprendida entre el siglo IX y el X. En Olías, que plantea dificultades para señalar su cronología, el material cerámico recuperado en superficie nos permite pensar que fue anterior al siglo IX. Ahora bien, la cuestión está en poder determinar cómo fue su ocupación. Dicho de otra manera, no podemos precisar si fueron asentamientos más o menos estables o sencillamente eventuales. Excepción hecha del yacimiento de Pico Águila, todos los asentamientos tienen restos de muros y se han documentado restos de ocupación, especialmente tejas para las cubiertas de viviendas. Incluso cabría pensar que pudo ocurrir en el mismo Pico Águila, porque la destrucción para el establecimiento de construcciones defensivas en época de la guerra civil es evidente. Pero en ningún caso, se ha podido apreciar la existencia de estructuras hidráulicas. De todas formas, la relación entre el medio físico y estos asentamientos aún no se ha podido estudiar. Por el momento parece que se hallaban lo suficientemente apartados de los puntos regulares de agua y a una altura tan considerable que todo indica que era imposible una agricultura de regadío. Así pues, cabría pensar en una economía silvo-pastoril, con un aprovechamiento del saltus. Pero necesariamente habría que hablar de un medio físico muy diferente al actual y al históricamente conocido desde el siglo XVI en adelante. Esto no es realmente un problema, porque hay evidencias de que pudo ser un espacio de monte mediterráneo mucho más denso del que podemos intuir (MALPICA 199/b). De todas formas, no es seguro que estas poblaciones ocupasen tales asentamientos de manera permanente, pudiendo tener otras actividades económicas y utilizando las disponibilidades del saltus de manera complementaria y eventual. Eso querría decir que estamos ante ocu- paciones ocasionales, no permanentes, que se utilizaban esencialmente como refugios. Así podría explicarse la presencia de una cerca en Los Picos del Castillejo. Los materiales cerámicos, que se fechan en un amplio período que va desde el siglo VII al $\mathrm{X}$, aunque con una fuerte presencia de los de los dos últimos siglos (IX y X), podrían hablarnos de la ocupación de esos hábitats de altura en unos momentos especialmente conflictivos, que van desde la instalación de los árabes hasta la formación del califato, con especial incidencia en la etapa de finales del emirato. Tal vez en la adopción de estos lugares como habitats de altura haya que ver la respuesta de las comunidades altomedievales instaladas en las cercanías de Sierra Lújar ante el clima de violencia que se generó en aquellas fechas. Hay que tener en cuenta, como se puso de relieve en otro trabajo (MALPICA y GÓMEZ BECERRA en prensa), que el área montañosa oriental de la costa era muy distinta en los tiempos altomedievales de la parte occidental, pues la incidencia de la vida urbana en época antigua había sido nula. Parece que el origen de Moscaril fue distinto. Hay que pensar que más bien se debe insertar en el proceso de desarticulación del poblamiento tardorromano, muy significativo en la zona de Almuñécar (GOMEZ BECERRA en prensa).

Hay otros yacimientos altomedievales que están en el interior del área montañosa de la Sierra de Lújar y de la Contraviesa, que no se pueden considerar propiamente de altura, aunque haya que integrarlos en un modelo de poblamiento altomedieval. De $\mathrm{O}$ a $\mathrm{E}$ son los siguientes: Cerro del Castillejo (término municipal de Vélez de Benaudalla), en la margen izquierda del Guadalfeo, antes de llegar a su tramo final, que es el único realmente situado en el medio de Sierra de Lújar; el del Peñón de Pedro Vélez (término municipal de Orgiva), sobre el barranco de Alcázar, que precisamente separa aquella cadena montañosa de la Sierra de la Contraviesa; y el yacimiento localizado en la Rambla de Polopos (término municipal de Polopos), en la cara $\mathrm{S}$ de esa montaña, en un barranco abierto al mar. A ellos habría que añadir los restos de otros puntos más orientales de la 
Contraviesa, como los ya mencionados del castillo de la Rambla del Valenciano (término municipal de Sorvilán) y el yacimiento de la Ermita del Palomar (término municipal de Albuñol). Se les puede asignar una cronología que va del siglo VIII al IX, en algún caso incluso hasta los inicios del $X$, pero no más allá, como pone de manifiesto la total ausencia de cerámicas vidriadas.

Se trata de establecimientos mejor reconocibles en el medio físico en que se insertan. No ocupan áreas muy elevadas y se encuentran normalmente cerca de puntos de agua, con frecuencia dominando la parte media de un barranco. Es verdad que actualmente ofrecen una imagen de un medio degradado que puede inducirnos a pensar que estuviesen en un entorno de monte mediterráneo. Obedece esencialmente al hecho de que se hallan en antiguas tierras de labor, de secano, ya abandonadas y colonizadas por el matorral. No cabe desechar, pues, que utilizasen el saltus como medio de vida, pero seguramente complementario, porque es posible que existiese una agricultura. El problema estriba en saber de qué tipo era ésta. Por decirlo de otra manera, no se puede precisar si el regadío había hecho ya su aparición y si estos asentamientos estaban en relación con él. Ahora se encuentran en espacios muy abruptos y degradados, lo que impide tener una idea clara de cómo eran. La erosión ha sido fortísima por efectos de los laboreos de los secanos y de la ruina de las áreas irrigadas, que han hecho de las ramblas y barrancos pasos intransitables.

Cabe la posibilidad de que esos asentamientos fuesen los primeros en los que se produjo una transformación del medio físico para la introducción de la agricultura de regadío. Este extremo no se ha podido comprobar hasta el presente en los casos mencionados, aunque hay que poner de relieve que hay habitats que tuvieron una perduración mayor, llegando hasta época nazarí, y en los que se han podido documentar cerámicas muy ante- riores. Establecer el modelo de poblamiento a partir de la creación de una red de alquerías, dependientes o, mejor dicho, relacionadas con estructuras fortificadas que ya existían, es la tarea primordial. Eso quiere decir que es imprescindible un análisis arqueológico de todas y cada una de ellas, lo que no siempre es posible, porque la perduración de los asentamientos juega en su contra. Las redes de irrigación han tenido un origen histórico, que no se ha podido documentar salvo en casos muy concretos ${ }^{21}$.

Esta cuestión es de gran importancia, porque se pueden ver, como hemos dicho, dos asentamientos distintos, aquéllos que perduraron y otros que, sin embargo, no prosiguen más allá del siglo $X$. No sabemos a qué se debió esta situación, pero aparece como un hecho incuestionable. Tal vez haya que relacionarlo con las bases físicas, que eran diferentes y permitieron una transformación con mayores garantías en unos sitios, mientras que en otros era mucho más difícil. En cualquier caso, la desaparición de esos habitats debió de suponer una reestructuración de toda la estructura de poblamiento, primando las áreas más accesibles y las tierras llanas.

Queda por señalar, en el marco de este poblamiento, la discontinuidad que ofrece con respecto a otras estructuras anteriores. Así, en época romana, sólo se puede hablar de una ocupación escasa, seguramente en relación con las posibilidades mineras de la zona. (GÓMEZ BECERRA y MALPICA 1992) Por el contrario, los yacimientos prehistóricos, sobre todo del Bronce, aparecen con frecuencia, e incluso coinciden con los altomedievales. La situación de estos yacimientos de montaña pueden interpretarse como el resultado de una ocupación de espacios que, aunque penetrados por los hombres, eran marginales desde la perspectiva de la organización del territorio de época romana, como también lo son en relación con lo que estaba ocurriendo en la parte occidental de la costa granadina (MALPICA y GÓMEZ BECERRA en

21 En la excavación de urgencia realizada en 1993 en el Cortijo de Ana, en Pago, término municipal de Órgiva, se ha podido documentar una organización agrícola posterior a la existencia de una necrópolis tardorromana. 
prensa). Claro está que el peso de la vida urbana en esa área era muy considerable y la densidad de ocupación del territorio también era mayor.

Por lo demás, hay que pensar que, atendiendo a las dimensiones de los yacimientos altomedievales y a las características de la cerámica hallada en superficie, se trata de asentamientos creados a partir de la desestructuración del poblamiento romano anterior y de la llegada de nuevos pobladores. Sin embargo, caracterizar unos u otros a partir de una adscripción étnica no sólo es imposible por el momento, sino que tampoco es importante. Más significativo es señalar que se trataba de comunidades libres, no sujetas a ninguna relación de dominación por parte de señores de renta ni, por supuesto, del Estado. Eso no quiere decir que no hubiese en su seno una organización en base a la familia extensa e incluso al linaje. Son estos grupos familiares los que van a recuperar espacios ocupados anteriormente y abandonados por la acción del poblamiento romano. Un poblamiento disperso, opuesto a otro concentrado y regulado por unas vías de comunicación, es propio de una sociedad en la que el peso del Estado no es fuerte, por no decir que es inexistente. En buena lógica, la disponibilidad de los recursos naturales está menos mediatizada, porque la generación de excedente no es una acción exigida por una clase social.

Hay otro grupo de asentamientos que, estando en áreas más o menos montañosas, perduraron. De ellos destacan, en primer lugar, aquéllos que se mantuvieron hasta una época anterior a la nazarí y los que se prolongaron hasta ésta.

Mencionaremos primero los asentamientos que son claramente posteriores al siglo $X$, pero que no llegaron hasta la época final de la Edad Media. Son establecimientos humanos con una relación muy clara con el medio físico. En todos los casos, se puede hablar de un espacio transformado para la agricultura de regadío. Su localización lo pone de manifiesto claramente. En efecto, se encuentran en la zona intermedia de algunos barrancos, cerca del agua, bien de la que corre por ellos, bien de fuentes de resurgencia, que brotan del contacto entre los materiales calizos y los esquistosos. Son los yacimientos de la Haza de Los Almendros, en Sierra de Lújar, en la actual aldea de Lagos, por debajo de los Picos del Castillejo, en el término municipal de Vélez de Benaudalla; el Cortijo de La Reala, en los montes de la Sierra del Jaral, por encima de la punta deltaica de Carchuna (término municipal de Motril), y El Castillejo, en una elevación por encima de la rambla de Torvizcón. Cronológicamente van de los siglos X y XII, si bien este último llegaría hasta el siglo XIII.

El otro grupo es el formado por las alquerías plenamente identificadas en época nazarí y que aparecen en la documentación castellana. Todas ellas han dado lugar a pueblos habitados y en algunos casos a cortijos. Así pues, han sido núcleos intensamente ocupados, con áreas de cultivo irrigadas que siguen en cultivo o que han permanecido cultivadas hasta fechas recientes. De ese modo, el trabajo arqueológico tenía unas evidentes dificultades. Aun partiendo de la documentación castellana y siguiendo un sistema regresivo, el problema era establecer una estrategia científica que permitiese hacer un análisis propio de la Arqueología del paisaje. De todas formas, no se ha podido aplicar con igual rigor el método de trabajo, porque no es fácil la prospección arqueológica en las áreas de cultivo intensamente labradas y que apenas permanecen en descanso. Se ha centrado la investigación primordialmente en los núcleos que se han ido abandonando, en los más marginales y en los despoblados a partir de la conquista castellana que, por lo común, pasaron a ser simples cortijos. Eso supone que el reconocimiento arqueológico es cuando menos problemático, porque la explotación agraria ha continuado e incluso en los últimos años se ha intensificado. En la zona occidental han podido prospectarse, además de Jate, que en realidad debe estudiarse entre los asentamientos de zonas llanas, ${ }^{22}$ Turillas, Cázulas y Bodíar. Estas tres últimas alquerías están situadas en la cuenca superior del río Verde.

22 No debe confundirse con el poblado situado en la parte alta de río Verde en el Peñón de los Castillejos, que ya ha sido analizado. 
Sólo la de Turillas, sin embargo, nos ha proporcionado datos suficientes. La cerámica hallada en superficie se puede fechar entre los siglos XII y XIII, aunque el topónimo parece precedente ${ }^{23}$.

Las situadas en los márgenes de la vega baja del Guadalfeo en el entorno de Salobreña, hay que adscribirlas igualmente a las de llanura, pero adelantemos que han sufrido una gran transformación, siendo a veces casi imposible su identificación ${ }^{24}$.

Los núcleos ubicados en Sierra Lújar y la Contraviesa fueron abandonadas en su práctica totalidad en las primeras décadas del siglo XVI (MALPICA 1986b). De todas formas, por los indicios que tenemos, se puede decir que en su mayoría mantuvieron su actividad productiva, aunque modificándola. En efecto, las áreas de regadío pervivieron, según parece, desarrollando una arboricultura en detrimento de los cultivos herbáceos. Aquélla permitía un mantenimiento de la agricultura de regadío, pues desde puntos más o menos próximos se podía acudir a hacer esos trabajos. Algunos de estos asentamientos se convirtieron posteriormente en pueblos, mientras que otros sólo fueron cortijos. Actualmente están en muchos casos en un acelerado proceso de abandono y han sufrido una paulatina marginación. Eso ha permitido un examen arqueológico con un cierto detenimiento. Sin embargo, lo frecuente es que se hayan encontrado restos muy escasos, hasta el punto que sólo la toponimia ha permitido su localización, sin que la prospección arqueológica mostrase evidencias dignas de tenerse en cuenta ${ }^{25}$. No obstante, podemos disponer de algunos datos en otros casos. De este modo, en el solar de las antiguas alquerías de Gualchos, en torno al pueblo del mismo nombre hoy en día (MALPICA 199|a), en el medio de Sierra Lújar, de Ubrite, que hemos identificado con el actual cortijo de Rubite Alto, en la línea divisoria de aquélla con la Contraviesa, de Bordomarela y Pinos, en pleno corazón de la Contraviesa, se ha podido identificar cerámica de los siglos $X$ al $X I$, con una continuidad en su ocupación hasta la llegada de los castellanos.

Todos los núcleos responden a un modelo muy consolidado en este territorio costero, al menos en las áreas de montaña. Suelen estar a media ladera de barrancos o en el contacto entre los medios calizos y los esquistos, que permiten la existencia de fuentes de resurgencia. Utilizan las disponibilidades de agua para irrigar una superficie que está por debajo del núcleo habitado, mientras que por encima de él existe un secano complementario y el monte mediterráneo. Las terrazas de cultivo son parte esencial del aprovechamiento del agua para la agricultura, pero al mismo tiempo configuran el espacio de una forma muy marcada. Asimismo, el sustrato es importante para el asentamiento, no sólo porque permite la resurgencia de aguas, sino también porque en la caliza se suelen establecer los núcleos y se cultivan las tierras procedentes de rocas metamórficas, que permiten una agricultura de regadío, ya que crecen sus rendimientos en función de la irrigación, mientras que son muy escasos si se dedican al secano. Una característica esencial es que las disponibilidades de agua condicionan los asentamientos y las áreas de cultivo. Aunque hay acequias que derivan el agua de los barrancos o ramblas, son más frecuentes las fuentes de resurgencia. De todas formas, hay que señalar que, a diferencia de lo que ocurre en otras partes del reino de Granada, como en la vecina Alpujarra ${ }^{26}$, no hay grandes redes de acequias que abastezcan varias alquerías.

Como queda dicho, es una agricultura que supone una profunda tranformación del medio físico, que acondiciona incluso la topo-

\footnotetext{
23 El término Turillas parece derivar del latín turris.

24 Es a causa del proceso de aluvionamiento por la desforestación progresiva, con un máximo a partir del siglo XVI y durante el siglo XVII, que han sufrido las tierras de la montaña próxima.

25 Es el caso, por ejemplo, de las alquerías de Alfaz y Détiar, respectivamente en las țāaa/s de Sāhil y Suḥayl (MALPICA CUELLO, A.: 1986, p. 135).

26 El caso de la Alpujarra es el más cercano y uno de los mejores estudiados. Pueden consultarse TRILLO 1992 y 1994.
} 
grafía en beneficio de las tierras de cultivo y que crea una estrecha dependencia del núcleo con respecto a todo el sistema. Esto implica una gran perduración del asentamiento y de la red hidráulica. Nos llevarían estas cuestiones a hablar de la necesidad de mantenimiento del conjunto y de su virtualidad social, según ya pusimos de relieve. De todas forma, se trataba de un nuevo sistema de aprovechamiento de los recursos de la zona de montaña, muy diferente del que había en época romana, que se basaba fundamentalmente en la explotación de la minería.

2. En las zonas más llanas hay asentamientos menos evidentes que los de montaña. Se debe obviamente a las grandes transformaciones, que sesgan la lectura $y$, en consecuencia, el análisis del poblamiento medieval de la costa de Granada (MALPICA 1992).

Al compás del avance de nuestra investigación y también de la destrucción creciente, han ido apareciendo restos muy elementales que muestran la existencia de núcleos habitados en muy diferentes fechas. Son establecimientos dedicados de manera primordial al aprovechamiento agrícola y ganadero de su entorno, siendo muy probable su articulación con espacios de regadío. El mejor estudiado es el yacimiento de El Maraute, en la barriada motrileña de Torrenueva, en Motril (GÓMEZ BECERRA 1992). Se halla en el escalón montañoso que cierra la vega de Motril por el E y a muy poca distancia del borde del mar. Aparece documentado como la alquería de Bațarna en las fuentes árabes a partir del siglo X y hasta el Xll. Aun cuando aparece citada como qarya, se le asocia siempre con la explotación de atutía u óxido de zinc. No quiere decir que se identifique totalmente el núcleo con la mina, sino más bien hay que pensar que en sus proximidades hubiese una o varias. Hay diversos yacimientos relacionados con la minería en el reborde montañoso. De época romana se ha identificado uno llamado La Herrería, en donde se han podido encontrar escorias de mineral tratado. Hay otro en el Cerro del Toro, en donde siempre han existido explotaciones mineras, que permite documentar, gracias a la cerámica de superficie, una ocupación de los siglos X y XIII.
La minería en la zona era conocida desde tiempos romanos cuando menos. Incluso la clara referencia a esta riqueza hecha por numerosos autores, especialmente por alRāzī, en el siglo X, puede probar que constaba en los registros fiscales del califato cordobés. Es tanto como decir que el Estado se fijaba especialmente en esta zona. De ahí las numerosas referencias en las fuentes escritas. Pero la actuación arqueológica de urgencia llevada a cabo en un área de este yacimiento de El Maraute ofrece suficiente información, junto con el seguimiento realizado en los últimos años en el mismo. Hay que poner de relieve que la destrucción del sitio ha sido enorme y gran parte de la zona baja ha desaparecido para construir viviendas turísticas de pésimo gusto. Anotemos que se pudo identificar un alfar romano y algunas tumbas medievales. Recordemos asimismo que en la parte baja que mira al mar, en concreto al SSE, hasta hace algunas décadas había unas salinas ya desaparecidas, documentadas en época nazarí (MALPICA 1981). Bien pudieron estar en explotación en tiempos anteriores.

En cualquier caso, es evidente que su ocupación medieval coincide grosso modo con las fechas de las fuentes escritas. Se marca asimismo un hiato con respecto al asentamiento romano allí existente. Éste fue abandonado en torno a los siglos III-IV.

Es uno de los yacimientos más interesantes de todos los que se hallan en la misma línea de costa. Pero hemos podido detectar algunos más hacia el $\mathrm{O}$ y hacia el $\mathrm{E}$.

En el área más occidental se ha podido identificar la alquería de Jate, que no debe de confundirse con el poblado y fortificación situado en la cabecera del río Jate. Aquélla está en su desembocadura, en la ensenada de La Herradura, en donde se pueden reconocer estructuras constructivas. En efecto, hay restos en superficie de varias construcciones, seguramente viviendas, edificadas con la técnica de la tābiya, con unas características similares a las existentes en el poblado de "El Castillejo". Se ha podido reconocer también una torre rectangular, 
obra de mampostería, que debe identificarse posiblemente con la levantada por Diego Bernal, su segundo propietario castellano, a principios del siglo $\mathrm{XVI}$, con permiso real (MALPICA 1982).

Sin embargo, es muy poco lo que queda en esa línea costera, si exceptuamos ese caso y el de Almuñécar. En contrapartida, en torno a esa llanura aluvial, como ocurre en el entorno de Salobreña se han podido documentar un buen número de yacimientos romanos. Sólo uno de época posterior se ha identificado en la vega del Guadalfeo. Nos referimos al Cerro del Vínculo (término municipal de Salobreña), mientras que la alquería nazarí de Pataura no es fácil de documentar, puesto que el importante proceso de colmatación que existió la sepultó en su práctica totalidad. Más allá de esta área hay otros asentamientos más fácilmente identificables, tal vez porque las transformaciones han sido menores en el territorio en los últimos años. Son los yacimientos del Cortijo del Cura (término municipal de Motril), en un escarpe rocoso de la Sierra del Jaral, por encima de Carchuna; el de La Rijana (término municipal de Gualchos-Castell de Ferro), y los del Cortijo de Los Pastores, Los Chortales y Los Pelaílos, en el piedemonte occidental de la llanura de Castell de Ferro (término municipal de Gualchos-Castell de Ferro).

Todos estos asentamientos se integran en una realidad poblacional que apenas se ha podido analizar hasta el presente. A ello han contribuido de manera muy poderosa las transformaciones habidas en las llanuras costeras. De todas formas, el reborde montañoso se ha mantenido a salvaguarda hasta fechas más recientes, cuando el avance del regadío está ocasionando modificaciones importantísimas.

Es posible que se trate de asentamientos asociados a la vida agrícola, probablemente continuadoras de la de época tardorromana, como lo pone de manifiesto la existencia de materiales cerámicos de los siglos VI-VII y llegando incluso hasta el siglo VIII. Se debe señalar, no obstante, que hay cambios muy significativos con respecto a los asentamientos romanos de época anterior. Sin embargo no cono- cemos aún el modelo de ocupación del territorio en esa época, porque no se ha investigado en este campo. De todas formas, se aprecia la existencia de una serie de villae, de tamaño medio, posiblemente porque la topografía no permitía otra cosa, en las proximidades de Almuñécar y Salobreña, como queda dicho, en concreto en las suaves colinas de sus alrededores. Son un número apreciable, desde luego superior al que se ha documentado en fechas posteriores. Aunque se aduzcan causas erosivas o destrucciones, y aun teniendo en cuenta sus tamaños, siempre muy inferiores a los de las citadas villae, se puede pensar en una reducción de asentamientos al final de la Antigüedad en nuestra zona costera. Tal vez tengan que ver con las transformaciones agrícolas que debieron de tener lugar al final del Mundo Antiguo. La dispersión y reducción espacial de los asentamientos debe ser paralela a la pérdida de las vías de comunicación marítimas y a la reducción del tráfico comercial. Algunos yacimientos que no parecen estar relacionados directamente con la agricultura, como el de La Rijana, cesó de funcionar en esas fechas.

La línea costera se revitalizó a partir del siglo $X$ y durante todo el período medieval tuvo importancia. Las fuentes escritas de época castellana muestran una ocupación de forma más o menos clara, que se ve reforzada por los datos arqueológicos. Al caso de la alquería de Jate hay que añadir el de La Rijana y el de Cautor, que se citan como pesquerías poco después de la conquista castellana. Tenían, sin embargo, espacios cultivados y áreas de regadío (MALPICA 199la). Pero ya en el sigo XVI únicamente aparecen alquerías interiores y las ciudades de la costa, porque la línea marítima está despoblada y ocupada militarmente.

\section{BIBLIOGRAFÍA}

ACIÉN, M. (1989): "Poblamiento y fortificación en el sur de Al-Andalus. La formación de un país de Hușūn". III Congreso de Arqueología Medieval Española. Oviedo, 1989, pp. $135-150$

ACIÉN, M. (1992): "Sobre la función de los husūun en el Sur de al-Andalus. La fortificación en el Califato". Coloquio Hispano-Italiano de Arqueología medieval. Granada, pp. 263-274 
ACIÉN, M. (1994): Entre el feudalismo y el Islam. ¿Umar ibn Hafșūn en los historiadores, las fuentes y en la Historia. Jaén.

ACIÉN, M. (en prensa): "Los țugur del reino nazarí. Ensayo de identificación". Castrum 5. Murcia 1992.

AGOSTINO, B. De (1992): "Introduzione", en BERNARDI, M. (edit.): Archeologia del Paesaggio. Florencia, vol. I, pp. 1721.

Al-MAQQART (1988): Nafh al-Tīb, II, p. 65-66. Traduc. Ma Jesús RUBIERA: La arquitectura en la literatura árabe. Datos para una estética del placer. Madrid.

ARTEAGA, O. (1990): "La transformación del medio ambiente costero de Salobreña (Granada). Causas naturales e históricas". Ciclo de conferencias pronunciadas con motivo del V Centenario de la incorporación de Salobreña a la Corona de Castilla (1489-1989). Salobreña, pp. 55-83.

BARCELÓ, M. (1984): Sobre Mayūrqa. Palma de Mallorca.

BARCELÓ, M. (1988): "Vísperas de feudales. La sociedad de Sharq al-Andalus justo antes de la conquista catalana", en MAILLO SALGADO, F. (edit.): España, Al-Andalus, Sefarad: Síntesis y nuevas perspectivas. Salamanca, pp. 99-1 12.

BARCELÓ, M. (1988): "La arqueología extensiva y el estudio de la creación del espacio rural", en Miquel BARCELÓ y otros: Arqueología medieval. En las afueras del medievalismo, Barcelona, pp. 25।-255.

BARCELÓ, M. (1989): "El diseño de los espacios irrigados en al-Andalus: un enunciado de principios generales". I Coloquio de Historia y medio físico. El agua en zonas áridas: Arqueología e Historia. Almería, vol. I, pp. XV-L.

BARCELÓ, M. [y otros] (1995): El agua que no duerme. Fundamentos de Arqueología hidráulica andalusí. Granada.

BARCELÓ, M. (en prensa): "De la congruencia y la homogeneidad de los espacios hidráulicos en al-Andalus", en El agua en la agricultura de al-Andalus. Granada.

BARKER, G. (1986): "L'archeologia del paesaggio italiano: nuovi orientamenti e recenti esperienze". Archeologia Medievale, XIII, pp. 7-30.

BARKER, G. (1988): "Problemi metodologici nelle ricognizioni sul campo nell'area mediterranea", en Ghislaine NOYÉ (edit.): Structures de l'habitat et occupation du sol dans les pays méditerranéens: l'apport de l'Archéologie extensive. Roma-Madrid, pp. |37-|45.

BARSANTI, G. (1979): Dalla storia naturale alla storia della natura. Saggio su Lamarck. Milán.

BENECHERIFA, M. (1986): "Almuñécar en época islámica". Almuñécar. Arqueología e Historia, III, pp. 203-270.

BERTRAND, M. (1990): "Trogloditismo artificial y estructuras medievales de poblamiento de la Hoya de Guadix. Estudios comparativos con otras zonas de Andalucía Oriental". Anuario Arqueológico de Andalucía. 1987. Sevilla, II, pp. 200-206.
BINFORD, L. (1988): En busca del pasado. Barcelona.

CARANDINI, A. (1984): Arqueología y cultura material. Barcelona

CRESSIER, P. (1984): "Le château et la division territoriale dans l'Alpujarra médievale: du hisn à la țā̄a. Mélanges de la Casa de Velázquez, $X X$.

GARCÍA GÓMEZ, E. (1967): El califato de Córdoba en el «Muqtabis» de Ibn Hayyān. Anales palatinos del califa alHakam II por Isà b. A hmad al-Rāzi (360/97I -364/975), Madrid

GÓMEZ BECERRA, A. (1992): El Maraute (Motril). Un asentamiento medieval en la costa de Granada. Motril.

GÓMEZ BECERRA, A. (en prensa): "Almuñécar en el marco de la transición de la Antigüedad tardía al mundo medieval".

GÓMEZ BECERRA, A. y MALPICA, A. (1992): "El poblamiento medieval en la costa oriental granadina". III Congreso de Arqueología Medieval Española, (Oviedo, 1989), Oviedo t. II, pp. 313-319.

GONZÁLEZ BERNÁLDEZ, F. (1981): Ecología y paisaje. Madrid.

GUICHARD, P. (1979): "Le problème de la sofra dans le royaume de Valence au XIII siècle". Awrāq, II, pp. 64-7I.

GUICHARD, P. (1986): "Perspectives de recherche sur la toponymie et la géographie historique d' al-Andalus oriental", en BAZZANA, A y POISSON, J. M. (edits.): Histoire et archéologie de l'habitat médiéval. Lyon, pp. 185-190.

GURAIEB, J.E. (1960): "Traducción de al-Muqtabas III". Cuademos de Historia de España, XXXI-XXXII.

HENSEL, W. (1986): "Archeologia. Contenuto e ambito", en DONATO, G. y otros: Teoria e pratica della ricerca archeologica. I. Premesse metodologiche. Turín, pp. 19-31.

HODDER I. (1988): Interpretación en Arqueología. Corrientes actuales. Barcelona.

HODDER, I. y ORTON, C. (1990): Análisis espacial en Arqueología. Barcelona. Es traducción de la obra publicada en 1975.

HOFFMAN, G. (1988): Holozänstratigraphie und Küstenlinienver lagerung an der Andalusische MittelmeerKüste, Bremen.

HUMBERT, A. (1988): "Sites et milieu naturel", en NOYÉ, G. (edit.): Structures de l'habitat et occupation du sol dans les pays méditerranéens: l'apport de l'Archéologie extensive. RomaMadrid, pp. 297-300.

IBN HAYYĀN (1981): Crónica del califa 'Abdarrahmān III anNāṣir entre los años 912 y 942 (al-Muqtabis V). Traduc. Ma Jesús VIGUERA y Federico CORRIENTE. Zaragoza.

IBN 'IDART̃ (|90|-1904): Histoire de l'Afrique et de l'Espagne intituleé "al-Bayano'I-Mogrib". Trad. par E. FAGNAN, vol. II, Argel. 
IDRT̄Sī ( | 864- | 866): Nuzhat al-muštāq. Edic. y traduc. R. DOZY y M. J. de GOEJE: Description de l'Afrique et de l'Espagne. Leyden.

KLEJN, L. S.: "To separate a centaur: on the relationship of archaeology and history in Soviet tradition". Antiquity (67), 255, pp. 339-348.

KULA, W. (1973): Problemas y métodos de Historia económica. Barcelona, p. 52I.

LEVI-PROVENÇAL, E. y GARCÍA GÓMEZ, E. (1950): Una crónica anónima de 'Abd al-Raḥmān III an-Nāṣir. Edición, traducción, notas e índices. Madrid-Granada.

LEVI-PROVENÇAL, E. y GARCIA GOMEZ, E. (1980): EI Siglo XI en $1^{a}$ persona. Las "Memorias» de cAbd Allāh (Traduc.) Madrid.

MALPICA, A. (1981): "Las salinas de Motril. (Aportación al estudio de la economía salinera del reino de Granada a raíz de su conquista), Baetica, 4, pp. I47-165.

MALPICA, A. (1982): "Musulmanes y cristianos en la tierra de Almuñécar: La alquería de Jate". III Coloquio de Historia Andaluza. Jaén, pp. 99-120.

MALPICA, A. (1986a): "Castillos y sistemas defensivos en las țā̄a/s alpujarreñas de Sāhil y Suhayl: un análisis histórico y arqueológico". I Congreso de Arqueología Medieval, (Huesca, 1985), Zaragoza, t. II, pp. 357-380.

MALPICA, A. (1986b): "Formas de poblamiento de los mudéjares granadinos en las tabas de los Céjeles". Actas del III Simposio internacional de mudejarismo, (Teruel, 1984). Teruel pp. 131-143.

MALPICA, A. (1990): "Salobreña de la época medieval a la moderna", en Ciclo de Conferencias pronunciadas con motivo del V Centenario de la Incorporación de Salobreña a la Corona de Castilla, pp. 99- 129.

MALPICA, A. (I99/a): "El territorio de la costa oriental de Granada en época nazarí a la luz de un testimonio castellano de mediados del siglo XVl'. Chronica Nova, 19, pp. 433-462.

MALPICA, A. (199|b): "Medio natural y paisajes rurales en Sierra Lújar a finales de la Edad Media", Revista del Centro de Estudios Históricos de Granada y su Reino, 5, pp. 7I-88.

MALPICA, A. (1992): "Historia, arqueología y paisaje en la costa de Granada". I Coloquio Hispano-Italiano de Arqueología Medieval. Granada, pp. 275-289.

MALPICA, A. (1993): "Historia y Arqueología medievales: un debate que continúa", en MONTANARI, M. y otros: Problemas actuales de la Historia. Terceras Jornadas de Estudios Históricos. Salamanca, pp. 29-47.
MALPICA, A. (1995): "Ensayo introductorio" al libro de GUICHARD, P.: Al-Andalus. Estructura antropológica de una sociedad islámica en Occidente. Granada (reedición del original de Barcelona, 1976).

MALPICA, A. y GÓMEZ BECERRA, A. (1989): "La formación de un territorio fronterizo medieval: La costa granadina de la época musulmana a la conquista castellana". Fronteras. Arqueología Espacial I3, Teruel, pp. 252-255.

MALPICA, A. y GÓMEZ BECERRA, A. (I99|): Una Cala que llaman la Rijana. Arqueología y Paisaje. Granada.

MALPICA, A. y GÓMEZ BECERRA, A. (en prensa): "Donde nunca antes había entrado un ejército... El poblamiento de la costa de Granada en el marco de la formación del Estado islámico", II Encuentros de Madinat al-Zahrā' , (Córdoba 1991).

PESEZ, J. M. (1988): "Introduction", en NOYÉ, G. (edit.): Structures de l'habitat et occupation du sol dans les pays méditerranéens: l'apport de l'Archéologie extensive. Roma-Madrid, pp. 129-135.

SALVATIERRA, V. (1990): Cien años de arqueología medieval. Perspectivas desde la periferia: Jaén. Granada.

SÁNCHEZ MARTíNEZ, M. (1976): "La cora de Ilbīra (Granada y Almería en los siglos $X$ y Xl, según al-`Udrī (1003-1085)". Cuadernos de Historia del Islam, 7 (19751976), pp. 5-82.

TRILLO, C. (1992): La Alpujarra. Historia, Arqueología y Paisaje. Análisis de un teritorio en época medieval. Granada.

TRILLO, C. (1994): La Alpujarra antes y después de la conquista castellana. Granada,

TRILLO, C. (en prensa I): "Las especies vegetales en el reino de Granada al final de la Edad Media, según el vocabulario de Pedro de Alcalá (siglos XV-XVI)". Formas de habitar e alimentação no Sul da Peninsula Iberica na Idade Media. Mértola, 1993 (en prensa).

TRILLO, C. (en prensa 2): "La vegetación en el reino de Granada en el tránsito de la época medieval a la moderna, según el vocabulario del Padre Guadix". Coloquio intemacional: Transformaciones agrarias y cultura material en Andalucía Oriental y Norte de Marmecos. Granada, 1994 (en prensa).

TRILLO, C. (en prensa 3): "El agua y el paisaje rural en la Alpujarra en época nazarin". Coloquio "El agua: mitos, ritos y realidades". Granada, 1992.

WICKHAM, Ch. (1988): "L'Italia e l'alto Medioevo". Archeologia Medievale XV, pp. I05-I24. 

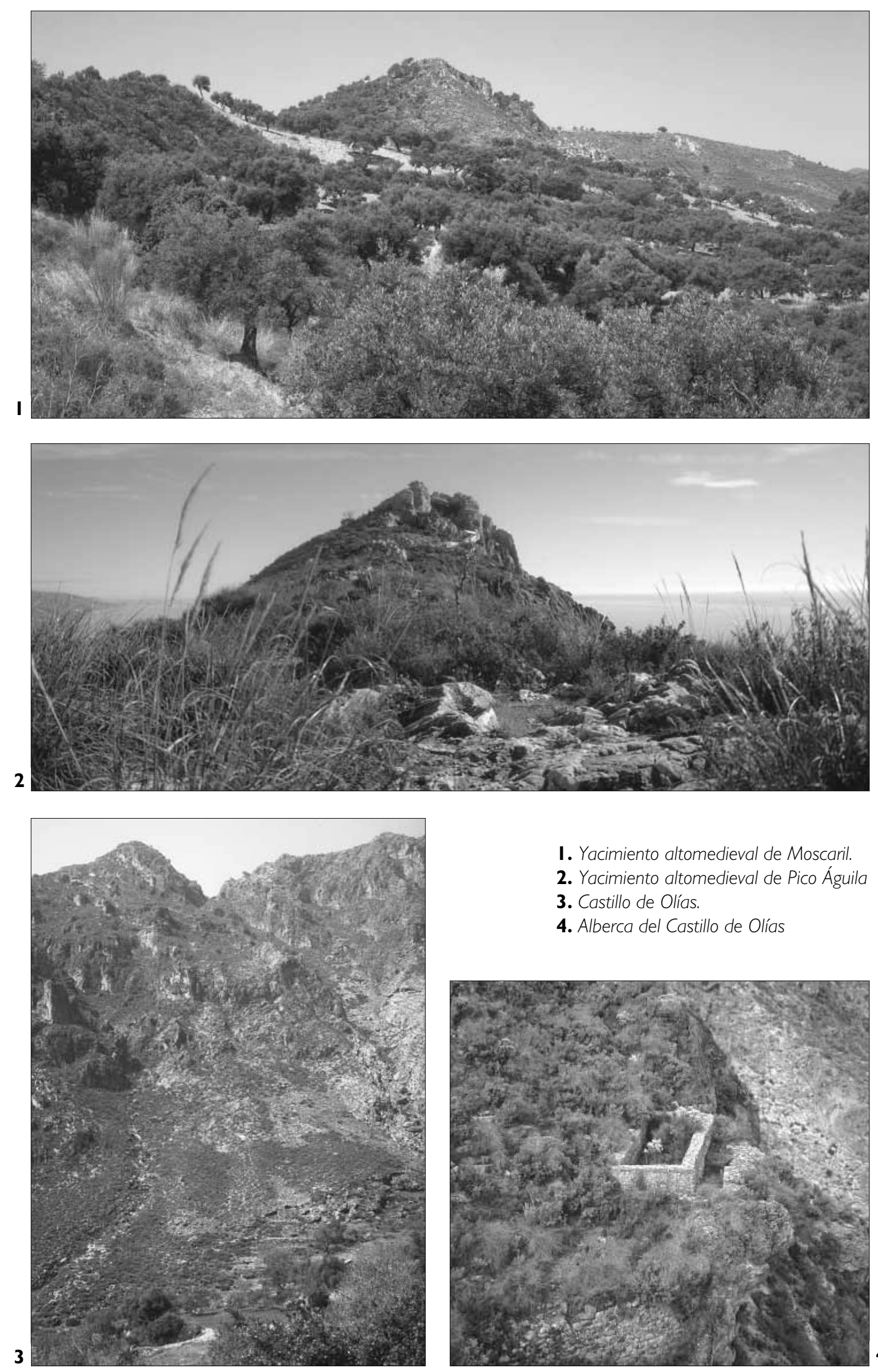

I. Yacimiento altomedieval de Moscaril.

2. Yacimiento altomedieval de Pico Águila

3. Castillo de Olías.

4. Alberca del Castillo de Olías

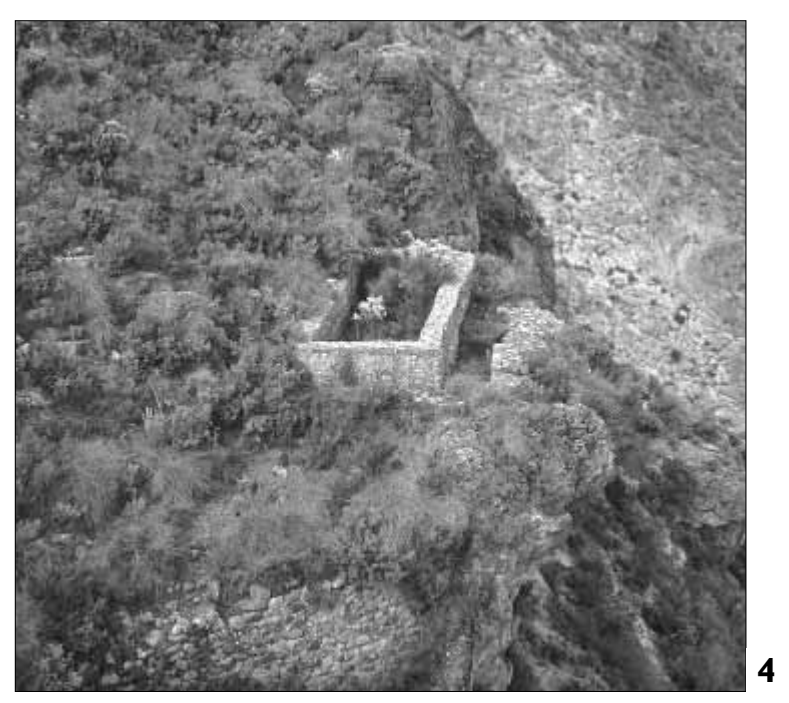



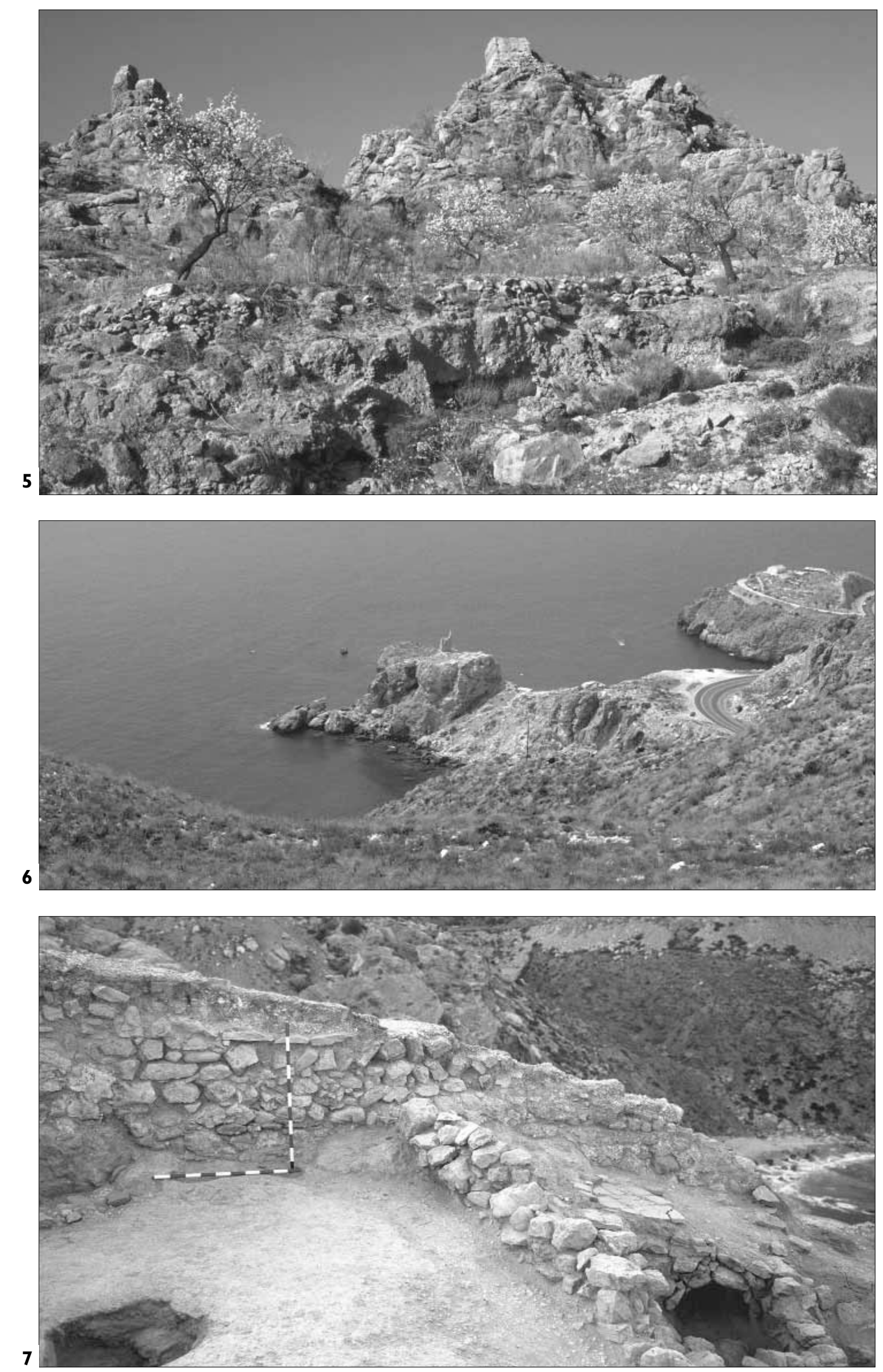


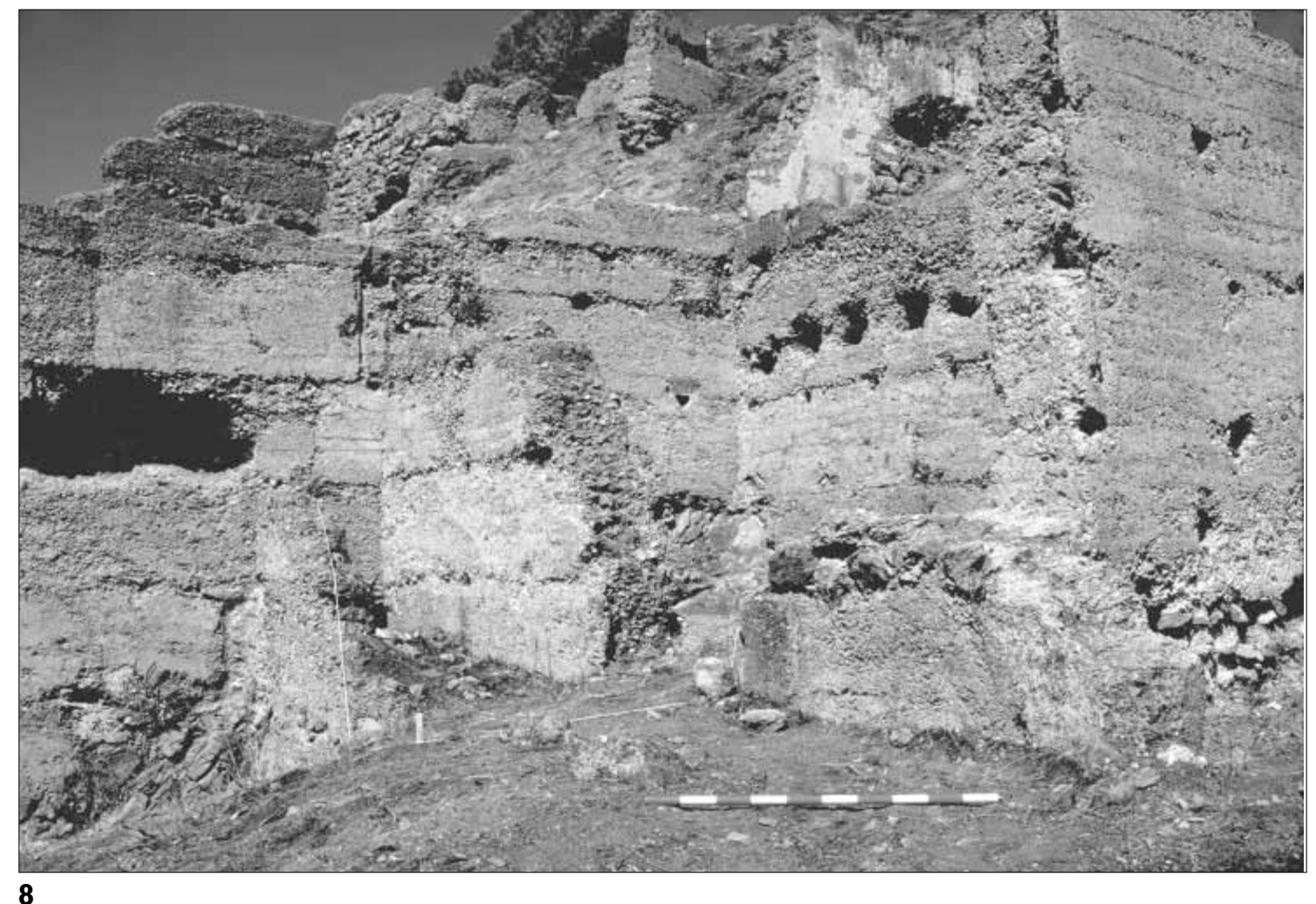

5. Castillo de Juliana

6. Cala de la Rijana

7. Cala de la Rijana. Sector N de la plataforma

8. Castillejo de los Guájares 


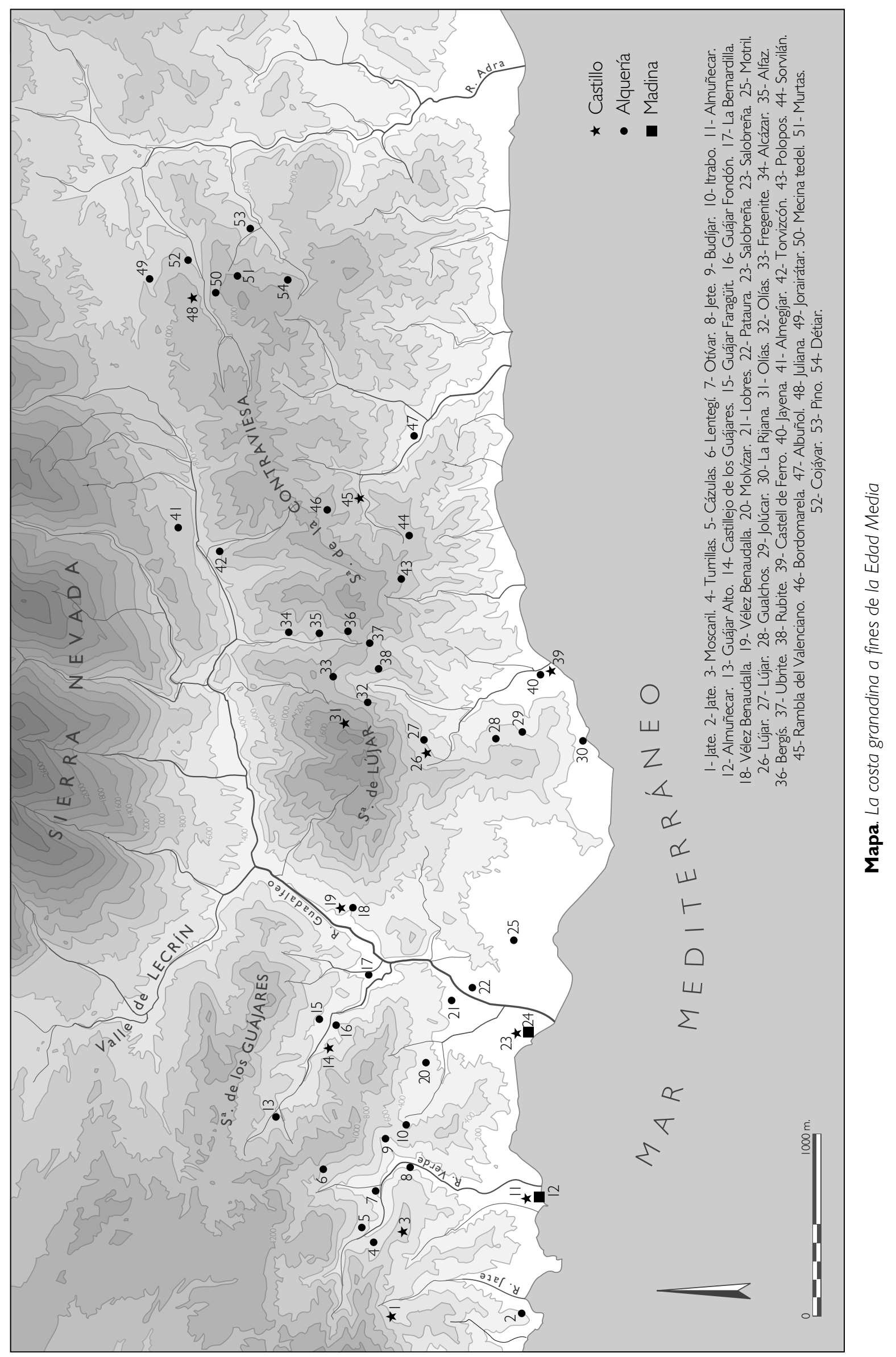

